San Jose State University

SJSU ScholarWorks

Master's Theses

Master's Theses and Graduate Research

Spring 2016

\title{
The Role of Bed Shear Stress in Sediment Sorting Patterns in a Reconstructed, Gravel Bed River
}

Samuel Emerson

San Jose State University

Follow this and additional works at: https://scholarworks.sjsu.edu/etd_theses

\section{Recommended Citation}

Emerson, Samuel, "The Role of Bed Shear Stress in Sediment Sorting Patterns in a Reconstructed, Gravel Bed River" (2016). Master's Theses. 4686.

DOI: https://doi.org/10.31979/etd.4una-4u7z

https://scholarworks.sjsu.edu/etd_theses/4686

This Thesis is brought to you for free and open access by the Master's Theses and Graduate Research at SJSU ScholarWorks. It has been accepted for inclusion in Master's Theses by an authorized administrator of SJSU ScholarWorks. For more information, please contact scholarworks@sjsu.edu. 


\title{
THE ROLE OF BED SHEAR STRESS IN SEDIMENT SORTING PATTERNS IN A RECONSTRUCTED, GRAVEL BED RIVER
}

\author{
A Thesis \\ Presented to \\ The Faculty of the Department of Geology \\ San José State University \\ In Partial Fulfillment \\ of the Requirements for the Degree \\ Master of Science
}

by

Samuel D. Emerson

May 2016 
(C)2016

Samuel D. Emerson

ALL RIGHTS RESERVED 
The Designated Thesis Committee Approves the Thesis Titled

THE ROLE OF BED SHEAR STRESS IN SEDIMENT SORTING PATTERNS IN A RECONSTRUCTED, GRAVEL BED RIVER

by

Samuel D. Emerson

APPROVED FOR THE DEPARTMENT OF GEOLOGY

SAN JOSÉ STATE UNIVERSITY

May 2016

Dr. Emmanuel Gabet

Dr. Paula Messina

Dr. Lee Harrison
SJSU Department of Geology

SJSU Department of Geology

NOAA Southwest Science Center 


\section{ABSTRACT \\ THE ROLE OF BED SHEAR STRESS IN SEDIMENT SORTING PATTERNS IN A RECONSTRUCTED, GRAVEL BED RIVER by Samuel D. Emerson}

The role of bed shear stress in bed surface grain size sorting was investigated on a reconstructed reach of the Merced River in the Central Valley of California. Pebble count data were collected at the inside, middle, and outside of ten bends in April 2015 and compared to data from pebble counts conducted in previous years. Output from a previously developed 2D flow model (FaSTMECH) was compared to critical shear stresses calculated from median grain-size data. Comparison of pebble count results from 2002 through 2015 showed that there was no temporally consistent pattern of coarsening or fining along the study reach; however, the bed surface coarsened between 2002 and 2015. Pebble count data from April 2015 revealed a distinct spatial distribution of grain sizes with a larger median grain size $\left(D_{50}\right)$ at the outside of bends and a smaller $D_{50}$ at the inside of bends. Regression analyses performed on pebble count data from point bars revealed statistically significant downstream changes in surface grain size on two of the seven bars. Analysis of shear stress data showed a weak relationship between the modeled bed shear stress $\left(\tau_{b}\right)$ and the calculated critical shear stress $\left(\tau_{c r}\right)$. The weak relationship between $\tau_{b}$ and $\tau_{c r}$ indicated that bed shear stress was not solely responsible for the grain size sorting in the study reach. It is likely that the observed grain size sorting patterns resulted from helical secondary flows at the bends. 


\section{ACKNOWLEDGEMENTS}

Many thanks to Paul Zimmer for his assistance in the field. Without his hard work, this project would not have been possible. Thank you to Dan Snyder for providing data from previous surveys on the study reach. Thank you to Dr. Lee Harrison for providing the model results used in this study as well as comments and suggestions for refining this manuscript. Great thanks to Dr. Manny Gabet and Dr. Paula Messina for their guidance and assistance in writing this manuscript. Finally, my deepest gratitude to my mother, father, and brother for always believing in me and supporting me no matter what. 


\section{TABLE OF CONTENTS}

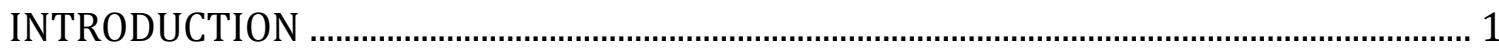

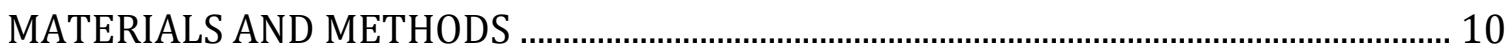

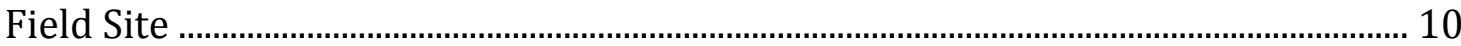

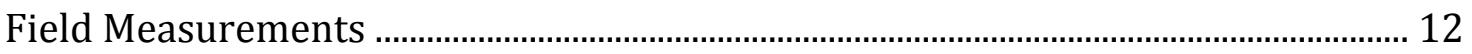

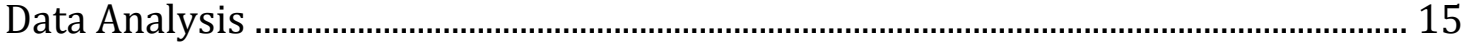

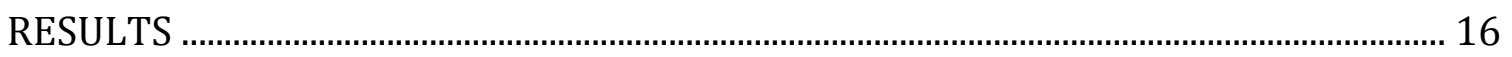

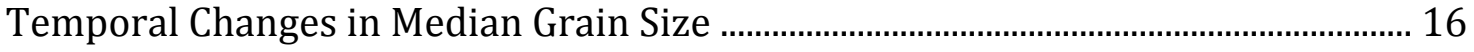

Spatial Distribution of Critical Shear Stress ................................................................. 16

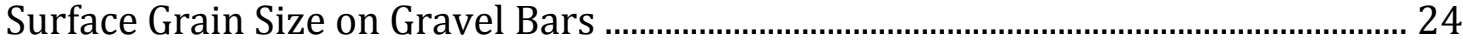

Spatial Distribution of Modeled Bed Shear Stress ....................................................... 29

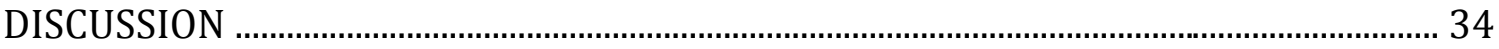

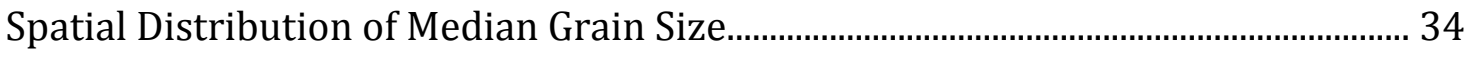

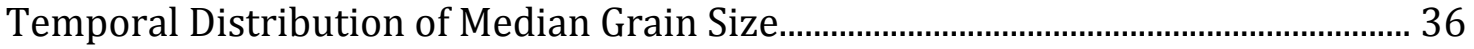

Modeled Bed Shear Stresses Versus Calculated Critical Shear Stresses...................... 37

CONCLUSION

REFERENCES CITED

APPENDIX 


\section{LIST OF FIGURES}

Figure

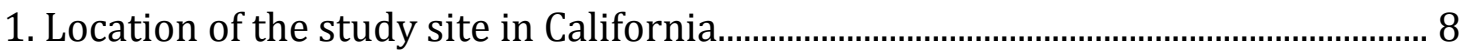

2. True color aerial photograph of the study reach.......................................................... 9

3. Location of surveyed bends in the study reach....................................................... 13

4. Location of nine surveyed gravel bars........................................................................... 14

5. Median grain size at different sections of the study reach through time............. 17

6. Median grain size at the inside, middle, and outside portions of the bends........ 23

7. Downstream change in surface grain size on Bar 1................................................ 25

8. Downstream change in surface grain size on Bar 2.................................................. 25

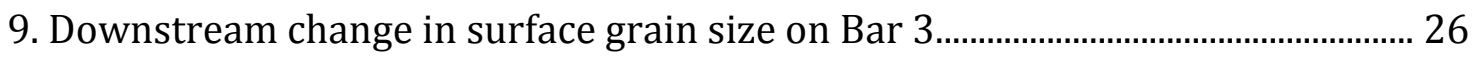

10. Downstream change in surface grain size on Bar 4................................................ 26

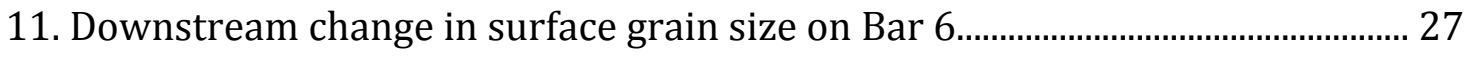

12. Downstream change in surface grain size on Bar 7 .................................................... 27

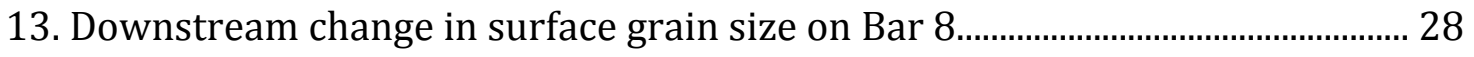

14. Spatial distribution of modeled bed shear stress...................................................... 30

15. Modeled $\tau_{\mathrm{b}}$ versus calculated $\tau_{\mathrm{cr}}$ at the bends in the study reach......................... 31

16. Modeled $\tau_{\mathrm{b}}$ versus calculated $\tau_{\mathrm{cr}}$ at the inside portions of the bends in the study reach......

17. Modeled $\tau_{\mathrm{b}}$ versus calculated $\tau_{\mathrm{cr}}$ at the middle portions of the bends in the study reach.

18. Modeled $\tau_{\mathrm{b}}$ versus calculated $\tau_{\mathrm{cr}}$ at the outside portions of the bends in the study reach 
19. Modeled $\tau_{\mathrm{b}}$ and calculated $\tau_{\mathrm{cr}}$ at the inside portions of the bends in the study

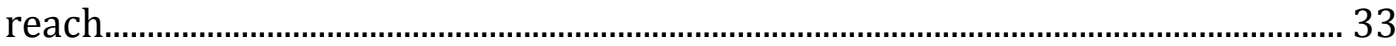

20. Modeled $\tau_{\mathrm{b}}$ and calculated $\tau_{\mathrm{cr}}$ at the middle portions of the bends in the study reach....................................................................................................................... 33

21. Modeled $\tau_{\mathrm{b}}$ and calculated $\tau_{\mathrm{cr}}$ at the outside portions of the bends in the study

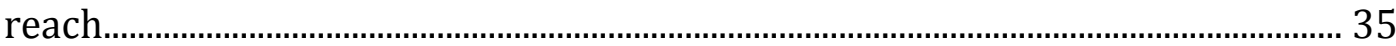

22. Close-up view of Bend 8 with distribution of modeled bed shear stress........... 40

23. Modeled $\tau_{b}$ at the inside, middle, and outside portions of the bends in the study

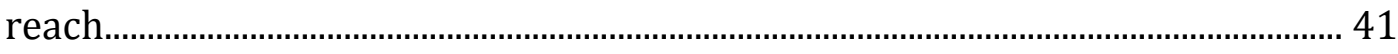




\section{INTRODUCTION}

In gravel bed rivers, the conditions necessary for ecological diversity are developed and maintained by the complex interactions between sediment flux and morphologic response (Powell, 1998; Harrison et al., 2011). Many techniques have been applied to river restoration projects with the purpose of improving salmonid habitats. One such technique is gravel augmentation, in which sediment of a sufficient size for spawning is added to river channels (Utz et al., 2012). Another restoration strategy, for rivers affected by dam construction, is to reengineer the channel and scale it according to the hydrologic conditions present after dam installation (Trush et al., 2000; Harrison et al., 2011). The goal of these techniques is to establish the initial conditions necessary for the development of natural river processes that will lead to complex aquatic habitats (California Department of Water Resources (CADWR), 2005; Harrison et al., 2011; Utz et al., 2012).

River restoration efforts in the United States have dramatically increased in the past three decades (Bernhardt et al., 2005; Bernhardt et al., 2007). Despite more than one billion dollars being spent every year on river restoration, success rates for many of these restoration projects are unknown due to a lack of published postproject assessments (Bernhardt et al., 2005; Kondolf, 2006; Bernhardt et al., 2007). Bernhardt et al. (2007) found that the motivation for river restoration projects has commonly been environmental perturbation; however, only 59\% of project contacts indicated that assessment of project success was based on quantitative data. They also found that $47 \%$ of project contacts used post-project site visits, photographic 
evidence, or positive public opinion as a basis for their assessments of project success.

Successful restoration of aquatic habitats is dependent upon geomorphic processes such as channel migration, pool scour, and bar building (Trush et al., 2000). Bed topography and channel curvature largely control flow structure and the spatial distribution of boundary shear stress (Powell, 1998). At the reach scale, spatial variability in boundary shear stress, $\tau_{b}$, creates bedforms and sediment sorting patterns that are integral to the maintenance and diversity of aquatic ecosystems. For instance, Trush et al. (2000) highlighted the geomorphic and ecological importance of the alternate bar sequence in healthy aquatic and riparian ecosystems. The alternate bar unit consists of a point bar and a scour pool, and when connected to another alternate bar unit by a transverse bar, forms an alternate bar sequence (Powell, 1998; Trush et al., 2000). In an idealized alternate bar sequence, secondary flows scour the bed at bends, creating pools that serve as holding habitat for adult salmon (Trush et al., 2000). Cross-stream centrifugal forces direct high velocity water toward the outer bank. The low velocity water flowing over point bars on the inner bank provides rearing habitat for fry and juvenile salmonids, while riffles connecting alternate point bars provide good salmonid spawning conditions (Trush et al., 2000).

The development of sediment sorting patterns at the subreach scale is largely controlled by the complex interactions between flow, boundary shear stress, and sediment transport fields (Powell, 1998). Riverbed surfaces are often structured 
spatially into well-sorted textural patches (Buffington and Montgomery, 1999; Nelson et al., 2009). Whiting (1988) observed that, in streams with beds of coarse sand and fine gravel, bedload moves downstream as thin clusters of well-sorted sediment referred to as bedload sheets.

Dietrich et al. (1989) used a flume experiment to show that textural patches are dependent upon sediment supply. Keeping discharge and bedload grain size distribution constant, they monitored sediment sorting at different sediment supply rates. At the high supply rate, they found that the bed surface was organized into thin, mobile bedload sheets. Bedload traveled in pulses of alternating coarse, fine, and intermediate patches that became less common and distinct as supply was reduced. A further reduction in sediment supply caused the development and expansion of inactive zones of coarse material and active sediment transport became confined to an ever narrower zone of fine material. Dietrich et al. (1989) noted that the formation of bedload zones results from the interactions between coarse and fine particles. As sediment supply decreases and the bed surface coarsens, finer particles fill the interstitial areas between coarse particles, smoothing the wakes of large particles and reducing local grain friction. These grain interactions can result in the remobilization of large particles (Whiting et al., 1988; Dietrich et al., 1989; Nelson et al., 2009).

In a similar study, Lisle et al. (1993) added water and a sand-gravel mix to the flume used by Dietrich et al. (1989) until sediment supply and bedload output reached equilibrium, allowing for the formation of stationary alternate bars. 
Following sediment supply reductions, the bed surface coarsened as finer particles were winnowed, exposing coarser material. With subsequent reductions in sediment supply, zones of fine material began to decrease in size and the bed surface progressively coarsened.

To assess channel recovery after the 1991 eruption of Mt. Pinatubo, Gran et al. (2006) observed the morphological response of the Pasig-Potrero River, which drains the eastern flank of the volcano, from 1996 - 2003. The field study was coupled with a flume study to investigate the links between bed surface structure and sediment transport with a decreasing sand supply. They found that, as sand supply to the river declined over the seven year observation period, the bed surface coarsened. The riverbed had begun evolving from a completely unarmored, sand bed to a gravel bed (Gran and Montgomery, 2005). Their flume study yielded similar results. Four runs were conducted with varying sediment loads. A sediment load of $70 \%$ sand resulted in an unarmored sand bed with isolated gravel clasts and loose gravel clusters. With $60 \%$ sand, pebble clusters developed, sometimes linking together to form transverse structures or weak armor patches. The flume run using a 50\% sand mixture produced substantial armor patches with a narrow sand ribbon between them. With $40 \%$ sand, sand cover was minimal, and gravel packing on armor patches was dense.

Various types of sediment patches have been observed in natural streams as well as in flumes. Nelson et al. (2009) described three types of sediment patches: free, fixed, and forced patches. Free patches are migrating patches such as bedload 
sheets in gravel bed rivers. Fixed patches are zones of coarse material that form due to surface coarsening and are relatively immobile due to weaker controls like grain interactions (Dietrich et al., 1989; Lisle et al., 1993). Forced patches are those that are controlled largely by divergences in shear stress caused by topographic features such as point bars and channel curvature (Nelson et al., 2009; Nelson et al., 2015).

To investigate the formation of forced patches, Nelson et al. (2015) developed a modified version of the Flow and Sediment Transport with Morphological Evolution of Channels (FaSTMECH) model. They tested the model by simulating Nelson et al.'s (2010) experiment in which alternate bars and forced patches formed on the bed of a straight, mixed-gravel bed flume. The flume experiment resulted in coarse material being deposited on bar tops while fine material was deposited in pools. They found that, although the $\mathrm{D}_{50}$ of the bedload was highly correlated with boundary shear stress, the bed surface $D_{50}$ and the boundary shear stress were not correlated.

Unlike the straight flumes used by Dietrich et al. (1989), Lisle et al. (1993), and Nelson et al. (2010), meandering rivers exhibit complex flow structures due to channel curvature and variable bed topography (Powell, 1998). As water flows through a meander bend, a cross-stream centrifugal force directs high velocity surface water toward the outer bank, resulting in super-elevation of the water surface. As the water surface is forced upwards on the outside of the meander, it is drawn down near the inside of the meander. This cross-stream centrifugal force 
creates a zone of maximum water surface slope and, therefore, a zone of maximum shear stress at meander bends (Powell, 1998).

In gravel bed rivers, excess shear stresses (shear stresses exceeding the critical shear stress required to mobilize bed surface material) are low and the spatial heterogeneity of sediment sizes is generally representative of the spatial distribution of the boundary shear stresses exerted on the bed. Sediment transport is, therefore, a close-to-threshold process (Powell, 1998). In rivers with uniform bed material, the relationship between boundary shear stress and particle mobility is largely dependent upon particle size. Sediment sorting due to particle size in rivers with mixed bedload, particularly gravel bed rivers, is complicated by a variable pocket geometry that results from the space between gravel and cobble sized particles. Sand sized particles deposited between larger particles are protected from near-bed flow because the larger particles protrude out of the substrate and into the flow. This increases the shear stress required to move the smaller particles while decreasing the shear stress required to move the larger particles (Powell, 1998).

Nelson et al. (2015) noted that the general sorting pattern observed in curved channels is opposite that observed in their flume study. The trajectory of particles in meandering rivers is controlled by near-bed fluid vectors as well as by bed slope direction (Powell, 1998). Particles moving over a transverse bed, or riffle, are directed toward the base of the slope due to gravity. The gravitational force, proportional to particle mass, causes coarser particles to be transported downslope more effectively than finer particles (Powell, 1998). Finer particles, having more 
surface area per unit mass than coarser particles, are moved inward by a helical secondary flow, while the coarser particles are carried to and deposited in topographic lows (Bunte and Abt, 2001). This process causes the surfaces of bar heads and bar bases to be coarser than the surfaces of riffles (Powell, 1998; Bundt and Abt, 2001). During high flows, high boundary shear stresses result in pool scour whereby the flow transports all but the largest particles out of pools, leaving behind the coarser bed material (Bunte and Abt, 2001).

This study tests the hypothesis that, in a meandering, gravel bed river with bed surface material composed predominantly of pebble sized clasts with a significant fraction of cobbles, the spatial distribution of median bed particle size will be strongly correlated with spatial variations in modeled bed shear stress. The bed should have coarser particles deposited in topographically low areas like bar heads and bar bases, and at the outside portion of meander bends in the zone of maximum shear stress, with finer particles present on the surfaces of point bars.

The recently reconstructed Robinson Reach of the Merced River in the Central Valley of California (Figure 1) provides a natural laboratory in which the evolution of fluvial processes and patterns, from a simple set of engineered initial conditions to a more complex and natural state, can be studied. To test the hypothesis, pebble counts were conducted at ten bends and nine associated point bars along the reach (Figure 2). Critical shear stresses at previously surveyed transects were calculated based on the median grain size and the Shields parameter. 


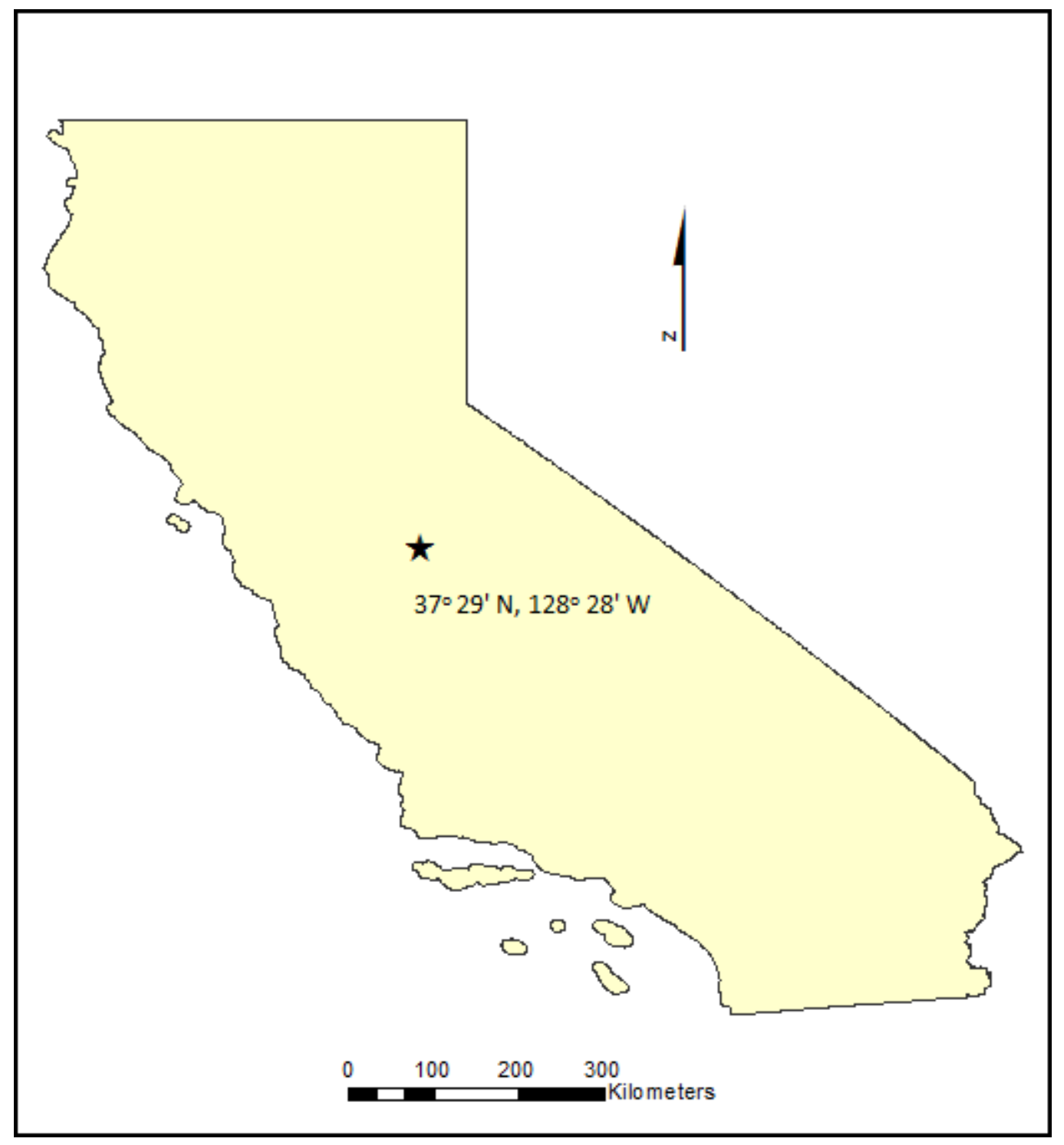

Figure 1. Location of the Robinson Reach, Merced River, CA. 


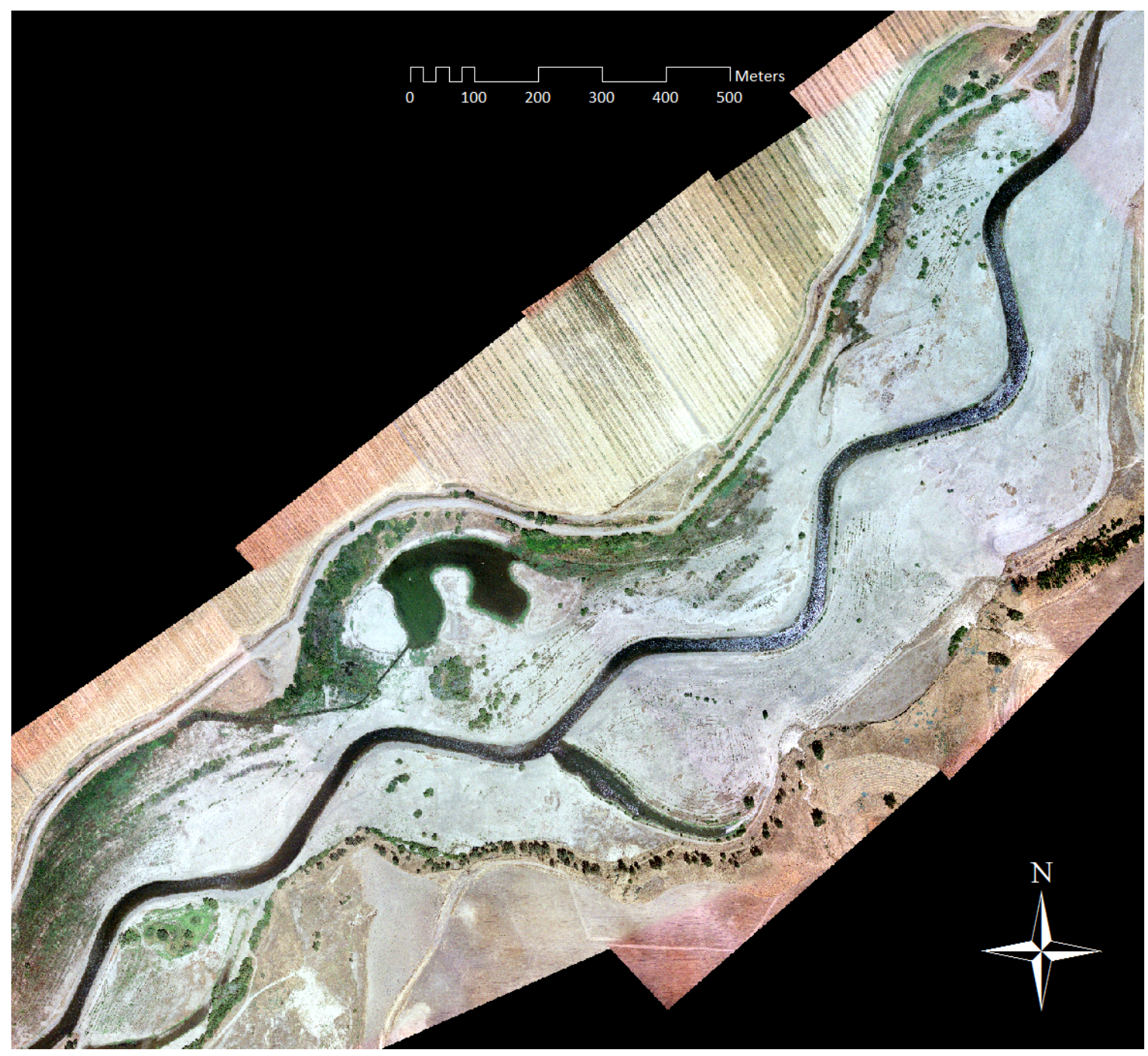

Figure 2. True color aerial photograph of the Robinson Reach, Merced, CA. Source: CADWR, 2006; public use approved by CADWR. 
The calculated critical shear stresses were compared to boundary shear stresses modeled with the Multidimensional Surface Water Modeling System (MD-SWMS) interface for the Flow and Sediment Transport with Morphological Evolution of Channels (FaSTMECH) model developed by the United States Geological Survey (Lisle et al. 2000; Nelson et al., 2003; Barton et al, 2005; Harrison et al., 2011). The model run was completed by L. Harrison and the results provided via personal communication. Pebble count data were also compared to data from pebble counts conducted from 2002 - 2006 and 2010 - 2012 at 32 transects along the Robinson Reach (Tom Snyder, CADWR, pers. comm.).

\section{MATERIALS AND METHODS}

\section{Field Site}

The Merced River has headwaters in the Sierra Nevada Batholith where it incises the granitic bodies comprising the High Sierra (Pittman and Ovenshine, 1968). As it flows westward beyond Yosemite Valley, the river encounters metamorphic bedrock such as phyllite, metachert, and metavolcanics. The bedload of the Merced River is thus composed of sediment of granitic and metamorphic origins, with the relative abundance of granitic sediment decreasing as distance from the Sierra Nevada Batholith increases (Pittman and Ovenshine, 1968).

This study was conducted on the Robinson Reach of the Merced River in the Central Valley of California. The study reach is comprised of the $2.25 \mathrm{~km}$ of river directly upstream from the CA Highway 59 Bridge, near the city of Snelling (Figure 1). At this location, the Merced River drains a watershed of approximately 3,305 
$\mathrm{km}^{2}$ (Harrison et al., 2011). The city of Snelling receives approximately $33 \mathrm{~cm}$ of precipitation annually. Annual temperatures range from $9.1^{\circ} \mathrm{C}$ to $24.5^{\circ} \mathrm{C}$ (usclimatedata.com).

Placer mining operations upstream of the study reach as well as the construction of Crocker-Huffman Dam in 1910 and McSwain and New Exchequer Dams in 1967 have reduced the sediment supply, thereby altering the relationship between sediment flux and channel morphology, and by extension, diminishing suitable spawning and rearing habitat for Chinook salmon (calwater.ca.gov; Harrison et al., 2011; Utz et al., 2012). A flood in 1997 caused the river to avulse into gravel pits located on the floodplain, converting the river from a single-thread to a braided channel, resulting in shallow, low velocity flows and occasional ponding (Harrison et. Al, 2011; Utz et al. 2012). Completed in 2002, the Robinson Reach Phase of the Merced River Salmon Habitat Enhancement Project (MRSHEP) was intended to ameliorate these negative conditions by restoring channel-floodplain processes.

The new channel, designed to have a single-thread, meandering planform, was constructed with an initial average bankfull width of $29.2 \mathrm{~m}$ and an average bankfull discharge of $42.5 \mathrm{~m}^{3} / \mathrm{s}$ (Harrison et al., 2011). Uniform bed material with a median grain size ( $D_{50}$ ) of $52 \mathrm{~mm}$ was chosen with the expectation of bed mobilization every 1-2 years. The channel was designed with pools and riffles and initially lacked point bars on the inside of meander bends. Each of the ten bends was built with a radius of curvature of $71 \mathrm{~m}$ (Harrison et al., 2011). The Robinson Reach 
has experienced three floods since its completion in 2002. Periods of overbank flow occurred in Spring 2005, Spring 2006, and Spring 2011 with maximum discharges of $120.5 \mathrm{~m}^{3} / \mathrm{s}, 142 \mathrm{~m}^{3} / \mathrm{s}$, and $140 \mathrm{~m}^{3} / \mathrm{s}$, respectively, and ranged from 81 days to 129 days in duration (Harrison et al., 2011; Harrison et al., 2015).

\section{Field Measurements}

To better understand the relationships between bed shear stress and sediment sorting patterns, the Wolman method (1954) was used to collect pebble count data that were then compared to similar data collected in previous years. Nineteen pebble counts were conducted in total, ten at the apices of the engineered bends (Figure 3) and nine at gravel bars associated with the engineered bends (Figure 4). One hundred grains were measured at evenly spaced intervals in the left, center, and right thirds of the wetted portion of each bend, for a total of three hundred grains at each bend. The only exception to this procedure was at the middle of Bend 3 where only ten grains were measured due to much of the bed surface at this location being hardpan. One hundred grains were measured along each of nine point bars. Pebbles on seven of the nine bars were measured to examine longitudinal changes in grain size. To ensure indiscriminate sampling, care was taken to avoid looking directly at the bed (Wolman, 1954). The median axis of each grain was measured using a Model 14-D40 Gravelometer. For consistency with previous work on the study reach, measured grains were assigned to one of the following size classes: 0-8 mm, 9-11.2, 11.3-16, 17-22.5, 22.6-32, 33-45, 46-64, 65$90,91-128,129-180,181-256$, or $>256 \mathrm{~mm}$. 


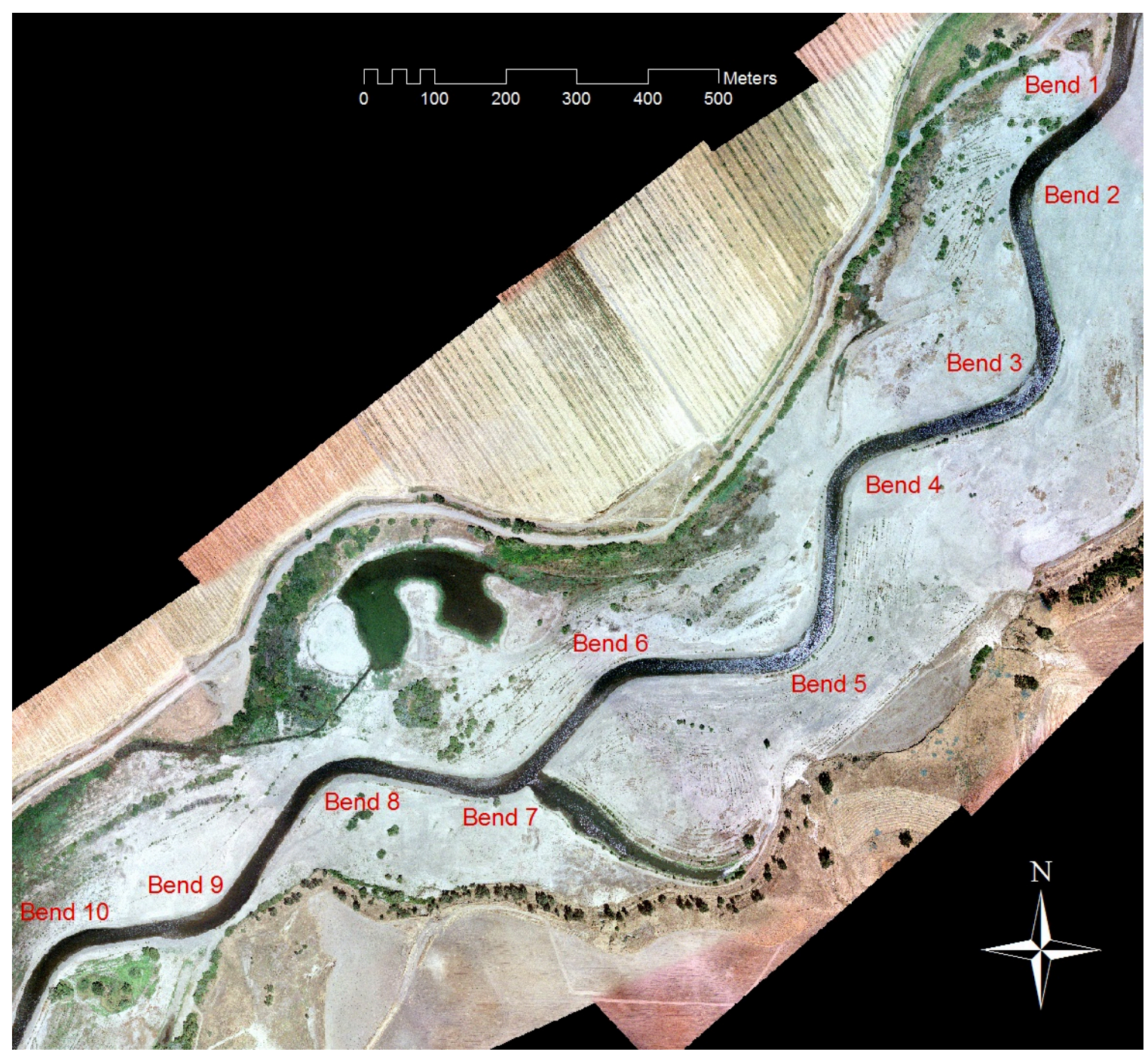

Figure 3. Bends 1 - 10 along the Robinson Reach. 


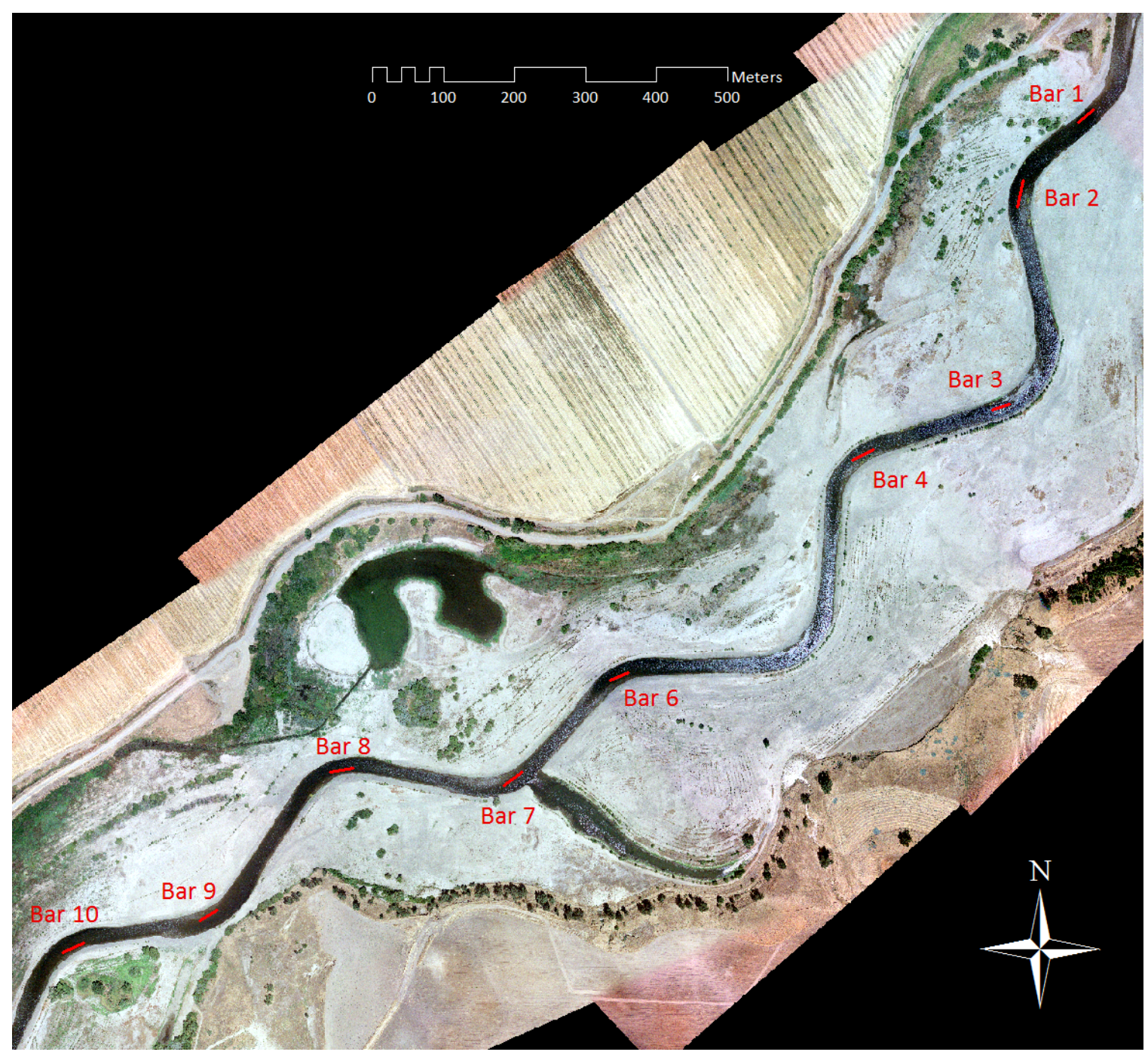

Figure 4. Locations of nine surveyed gravel bars along the Robinson Reach. 


\section{Data Analysis}

The $\tau_{\text {cr }}$ associated with median grain sizes at each transect was calculated with

$$
\tau_{c r}=\theta^{*}(s-1) \rho g D_{50}
$$

where $\theta^{*}$ is the Shields parameter for the study reach, 0.025 (Wydzga, A., personal communication); $s$ is the specific gravity of the sediment, 2.65 ; $\rho$ is the density of water, $1000 \mathrm{~kg} / \mathrm{m}^{3} ; g$ is gravitational acceleration, $9.8 \mathrm{~m} / \mathrm{s}^{2}$; and $D_{50}$ is the median grain size in m (Berenbrock and Tranmer, 2008).

FaSTMECH predicts the spatial distribution of water surface elevation, flow depth, flow velocity, and boundary shear stress based on inputs of discharge, bed topography, and downstream stage. The model solves the full vertically-averaged and Reynolds-averaged momentum equations and includes a streamline-based vertical structure submodel that calculates the vertical velocity distribution and secondary flows. This quasi-3-dimensional velocity field was used to calculate boundary shear stress (McLean et al., 1999, Harrison et al., 2011). Bankfull discharge $\left(42.5 \mathrm{~m}^{3} / \mathrm{s}\right)$ and bed topography data from a 2012 survey were used in this model run (Harrison et al., 2015). Real-time kinematic global positioning receivers with a vertical accuracy of $0.01 \mathrm{~m}$ were used for the bed topography survey (see Harrison et al. (2015) for details). This bed topography was used with 
the assumption that the bed surface had not significantly changed since a 2011 flood with a peak discharge of $140 \mathrm{~m}^{3} / \mathrm{s}$ (Harrison et al., 2011; Harrison et al., 2015).

The modeled bed shear stress data were interpolated using inverse distance weighting. The calculated critical shear stresses were then compared to the modeled shear stresses in scatter plots. Regression analyses were performed on data from seven of the nine point bars to determine if there was any statistically significant change in grain size along each bar.

\section{RESULTS}

Figure 5 shows changes in median grain size at each section through time. There is no consistent pattern of coarsening or fining along the entire study reach in any given year. The median grain size increased from its initial size in January 2002 to July 2002 at all surveyed sections except Sections 5 and 8 . Although pebble counts in 2005 were conducted only on Sections $1-13$, the $D_{50}$ decreased at Sections $2 b, 4 b, 4 c, 5,6 b, 7,9,10$, and 13. Pebble count data from other years revealed increases in median grain size at some sections while showing decreases at other sections.

The April 2015 pebble count data show a distinct spatial distribution of surface grain sizes with the largest particles in pools at the outside of meander bends and the smallest particles at the inside of meander bends on point bars at all but two of the bends (Figure 6). Bends 6 and 9 show a spatial distribution of surface grain sizes opposite that observed at other sections with the smallest particles at the outside of bends and the largest at the inside of bends. 


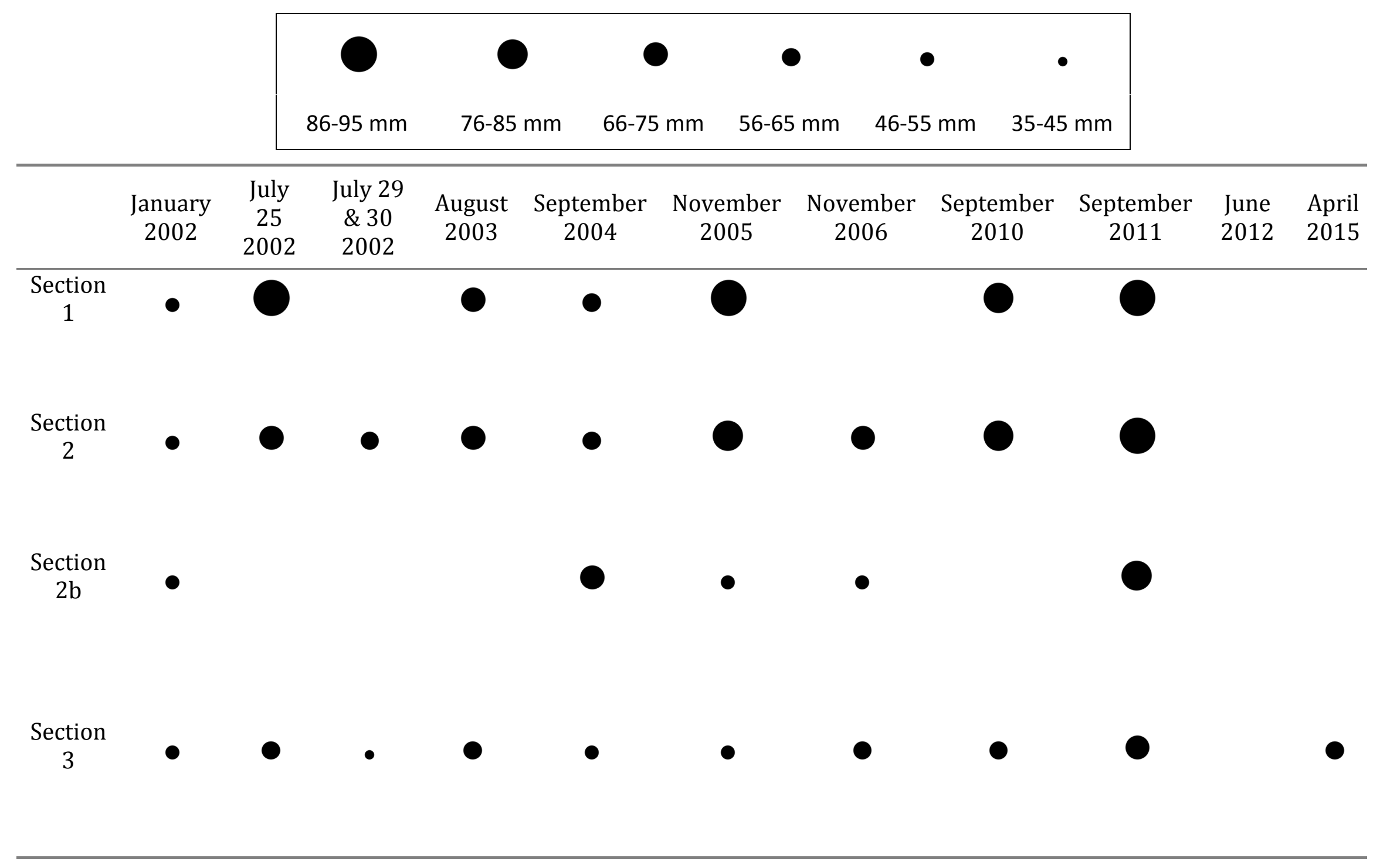




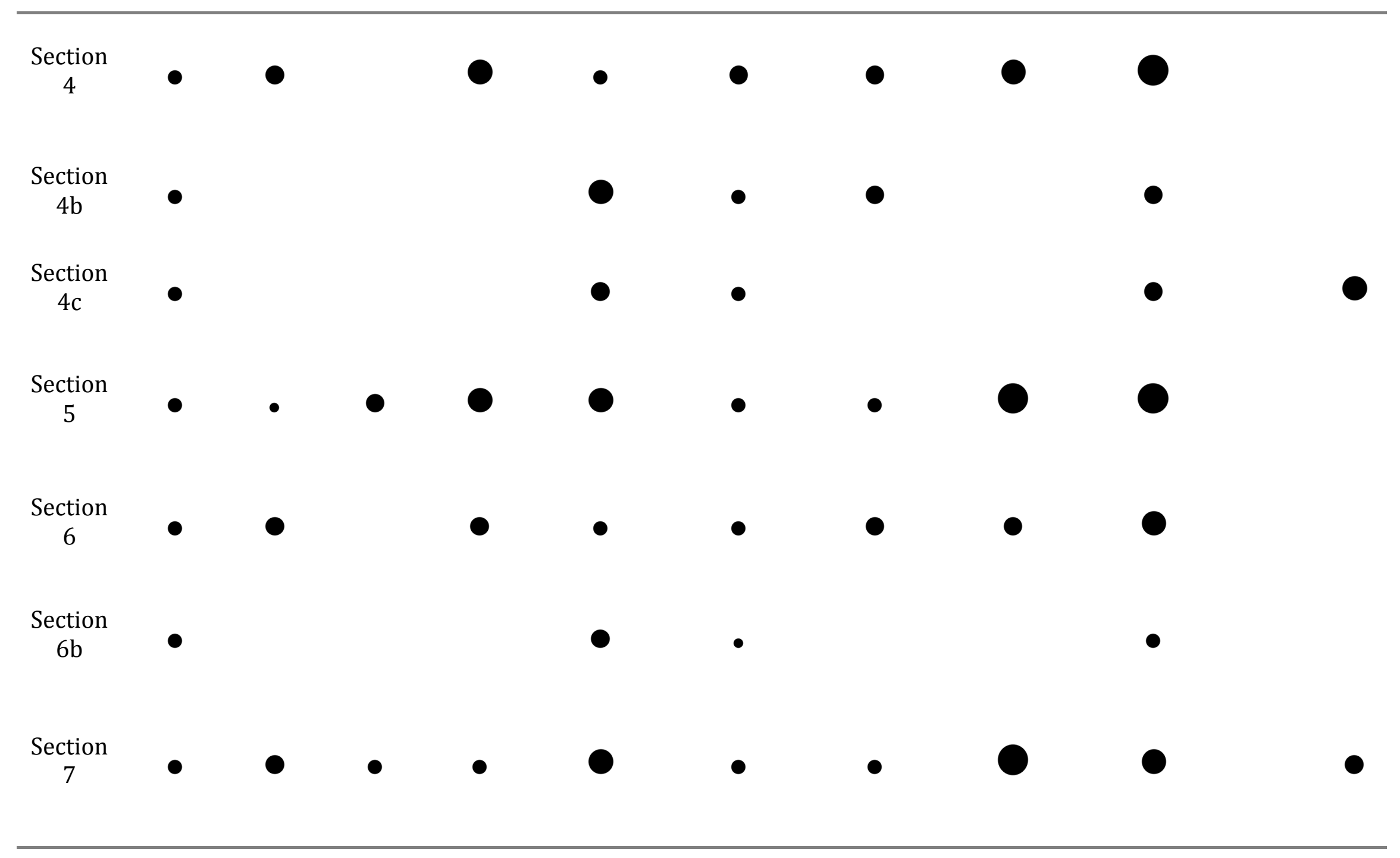




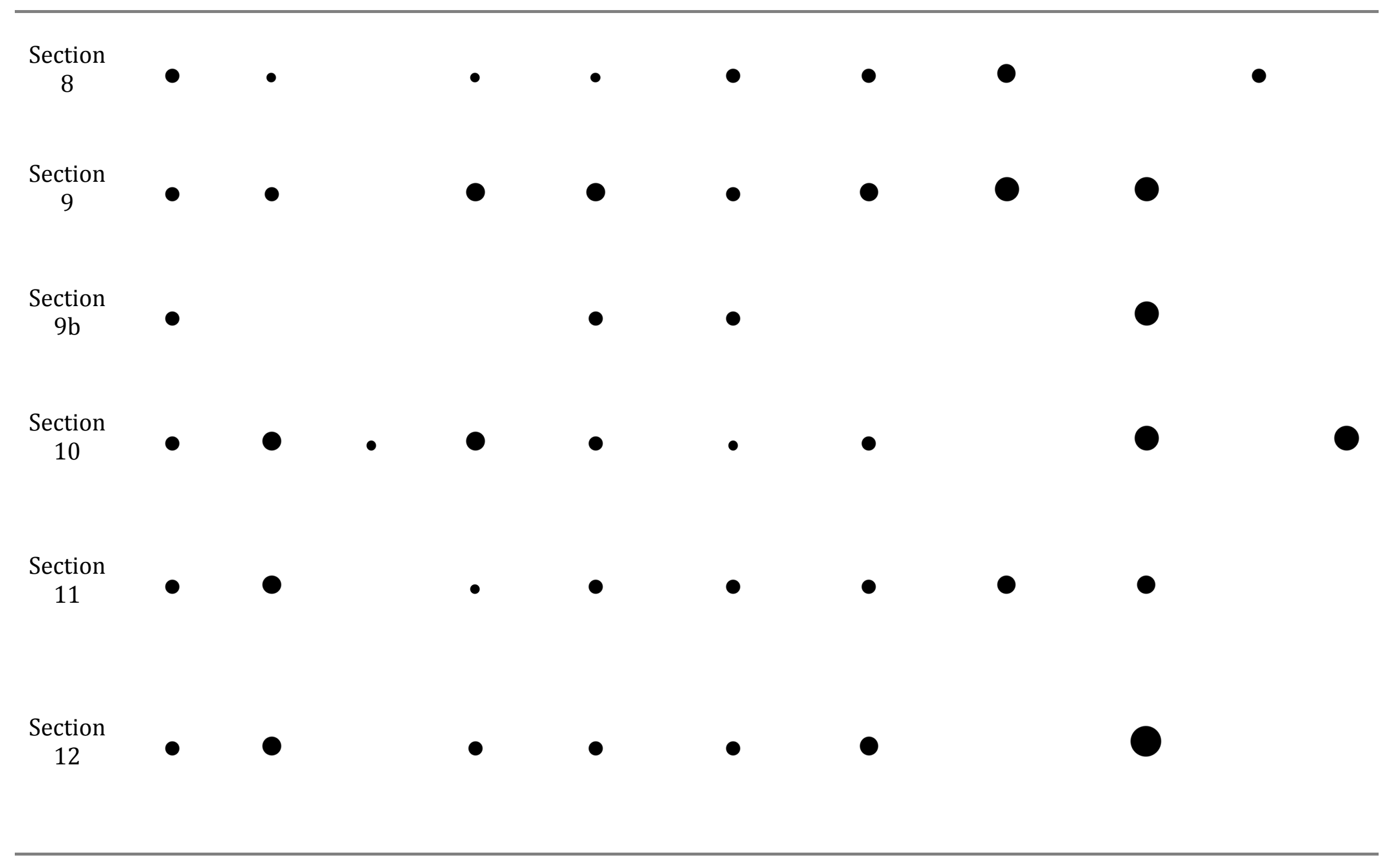




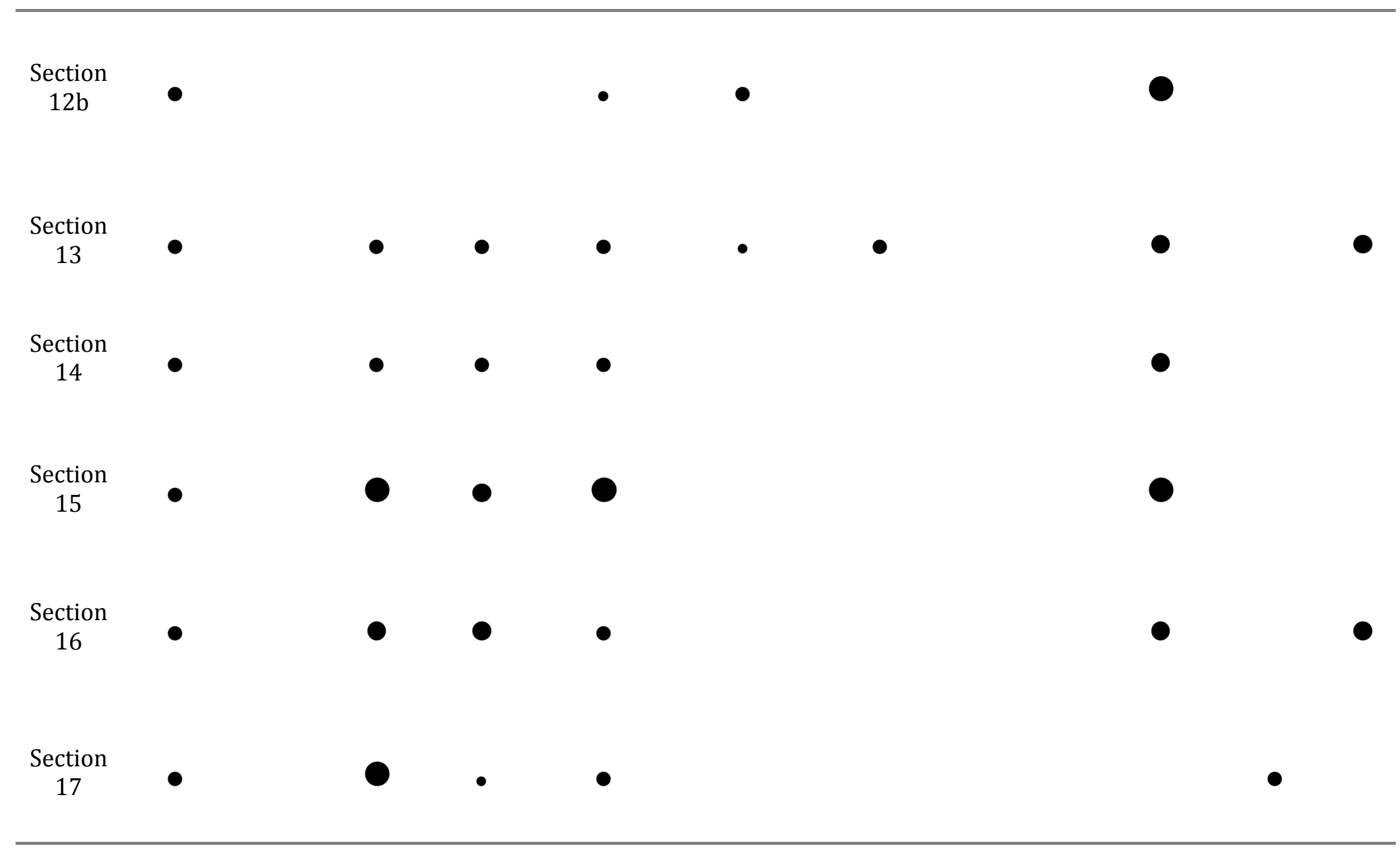




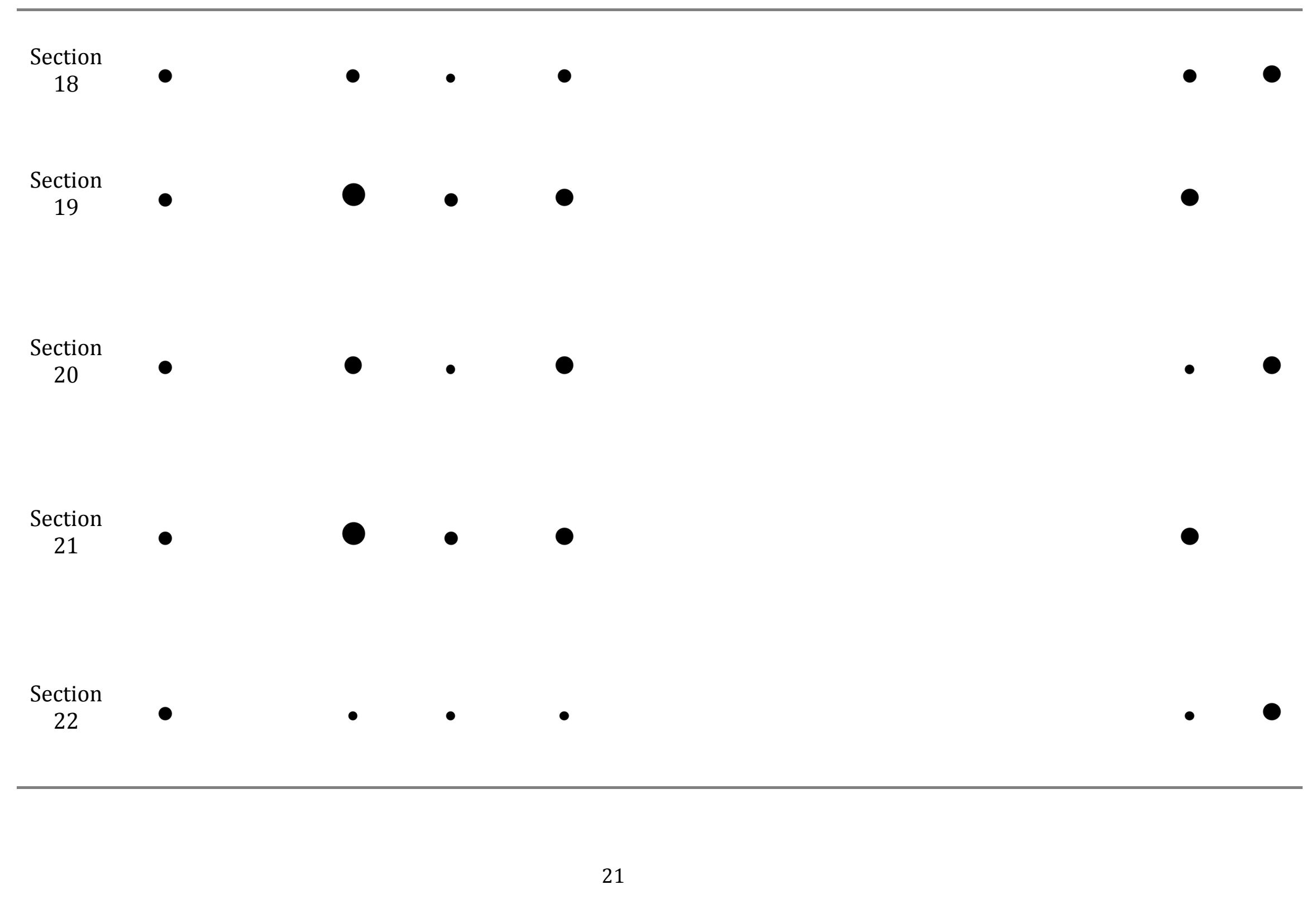




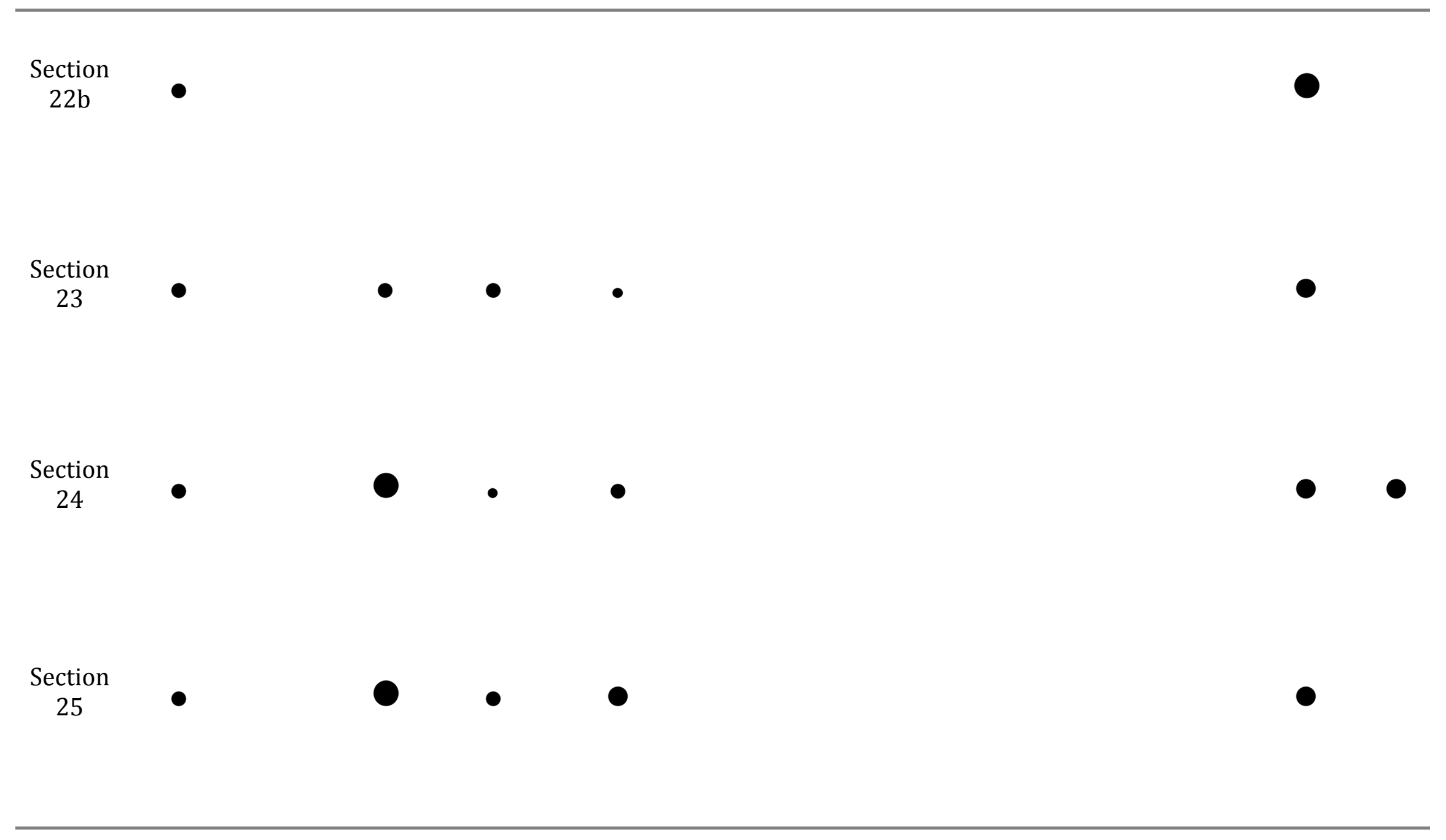

Figure 5. Graduated symbols representing the $\mathrm{D}_{50}$ at different sections of the study reach during different sampling periods. 


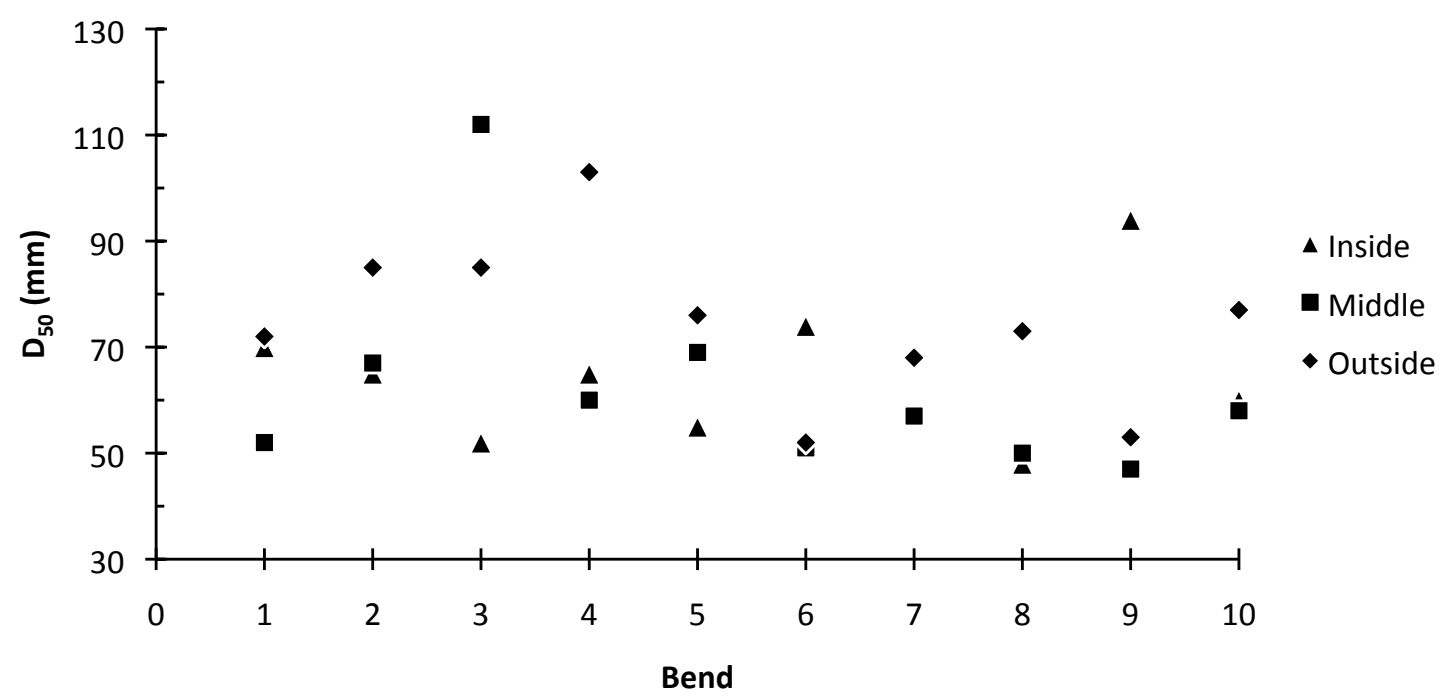

Figure $6 . D_{50}$ at the inside, middle, and outside portions of the bends in the study reach. 
The $D_{50}$ at the middle of Bend 6 was similar to the $D_{50}$ at the outside of the bend (Figure 6). The smallest $\mathrm{D}_{50}$ at Bends 1, 4, 9, and 10 was located in the middle portion of the channel. At Bend 3, the $\mathrm{D}_{50}$ in the middle portion of the bend was larger than the $\mathrm{D}_{50}$ at the inside and outside portions of the bend. The $\mathrm{D}_{50}$ in pools at the outside of bends ranged from $52 \mathrm{~mm}$ at Bends 3 and 6 to $103 \mathrm{~mm}$ at Bend 4 . The $\mathrm{D}_{50}$ at the inside of the bends ranged from $48 \mathrm{~mm}$ at Bend 8 to $94 \mathrm{~mm}$ at Bend 9. At Bends 1, 4, 6, and 9, the smallest $D_{50}$ was located in the middle portion of the channel. The mean $\mathrm{D}_{50}$ for all ten bends was $70 \mathrm{~mm}$.

Pebble counts with survey lengths ranging from $26.8 \mathrm{~m}$ to $38.2 \mathrm{~m}$ were conducted on nine gravel bars. Grain sizes on Bars $1-4$ and $6-8$ were measured and recorded to show longitudinal changes in grain size. Bar 5 was inaccessible due to bee infestation. Bar 2 was surveyed approximately at the apex of Bend 2. Bars 4, 7,8 , and 10 were surveyed just upstream of the apices of their associated bends. Bars 1, 3, 6, and 9 were surveyed just downstream of the apices of their associated bends.

Linear trendlines show downstream trends in grain size along each bar (Figures 7 - 13). Regression analyses of the trends in grain size on point bars revealed that the slopes of the regression lines for Bars 3 and 7 were significantly different from zero, with p-values of 0.0006 and 0.00004 , respectively, with a 95\% confidence interval. Regression slopes for Bars 1, 2, 4, 6, and 8 did not depart significantly from zero. 


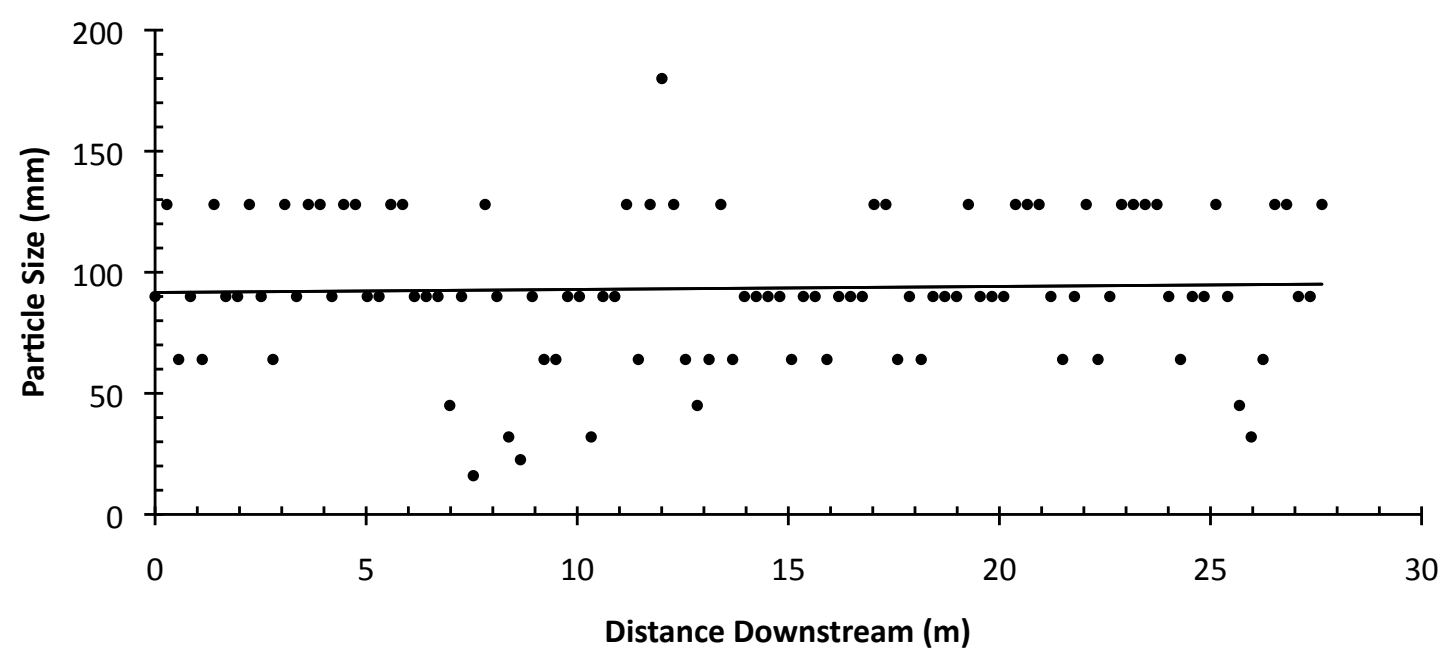

Figure 7. Surface grain size in the downstream direction on Bar 1 showing no statistically significant change.

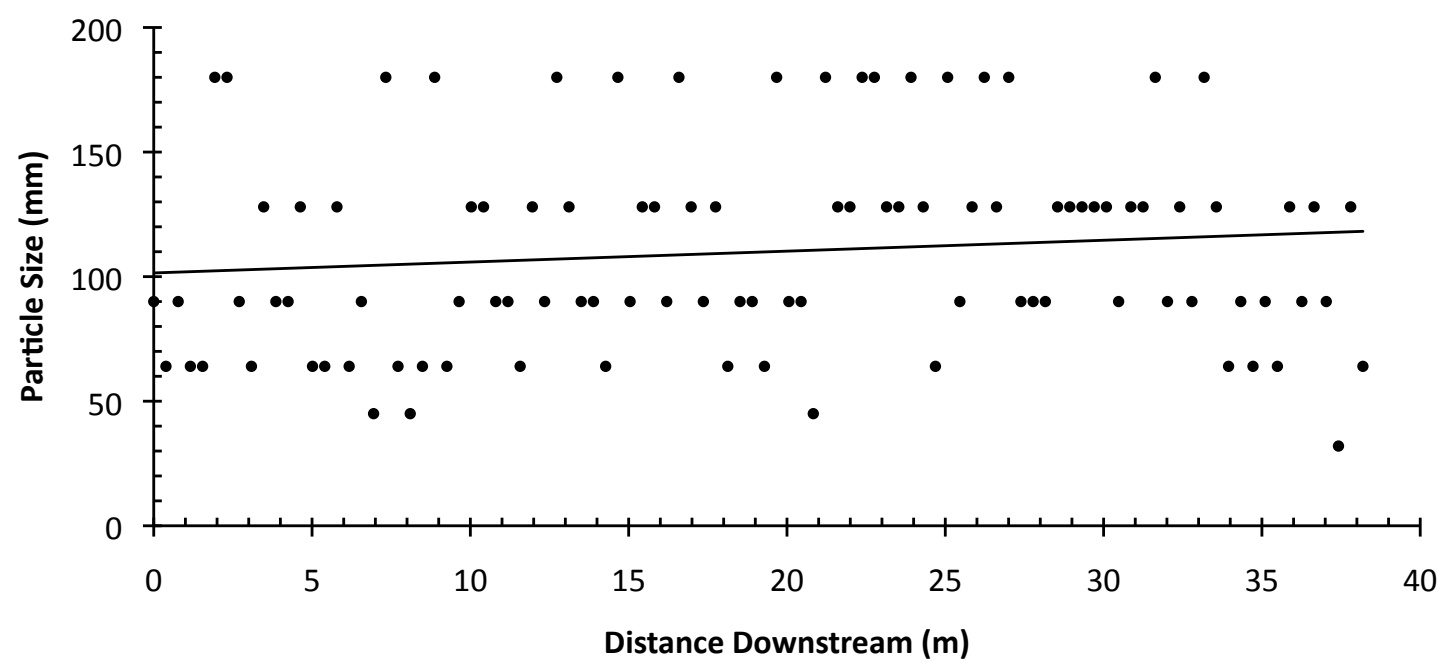

Figure 8. Surface grain size in the downstream direction on Bar 2 showing no statistically significant change. 


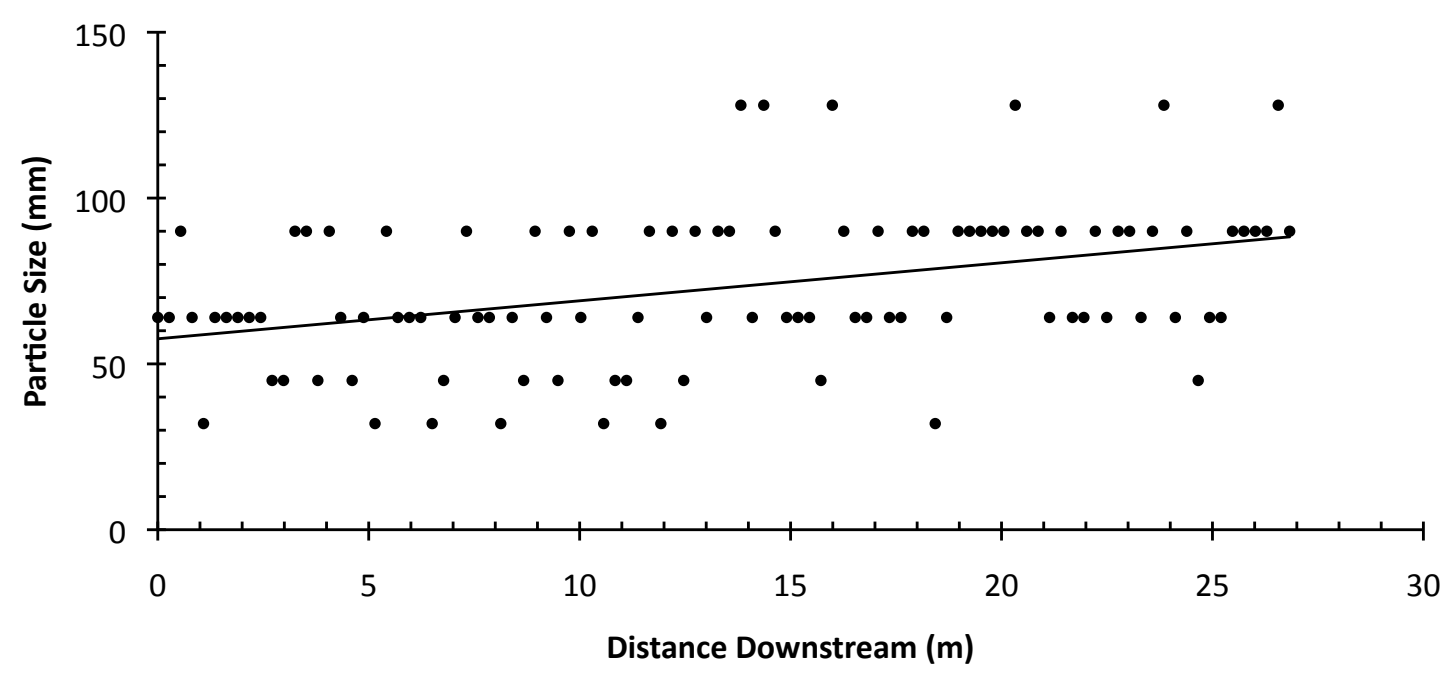

Figure 9. Surface grain size in the downstream direction on Bar 3 showing a statistically significant change.

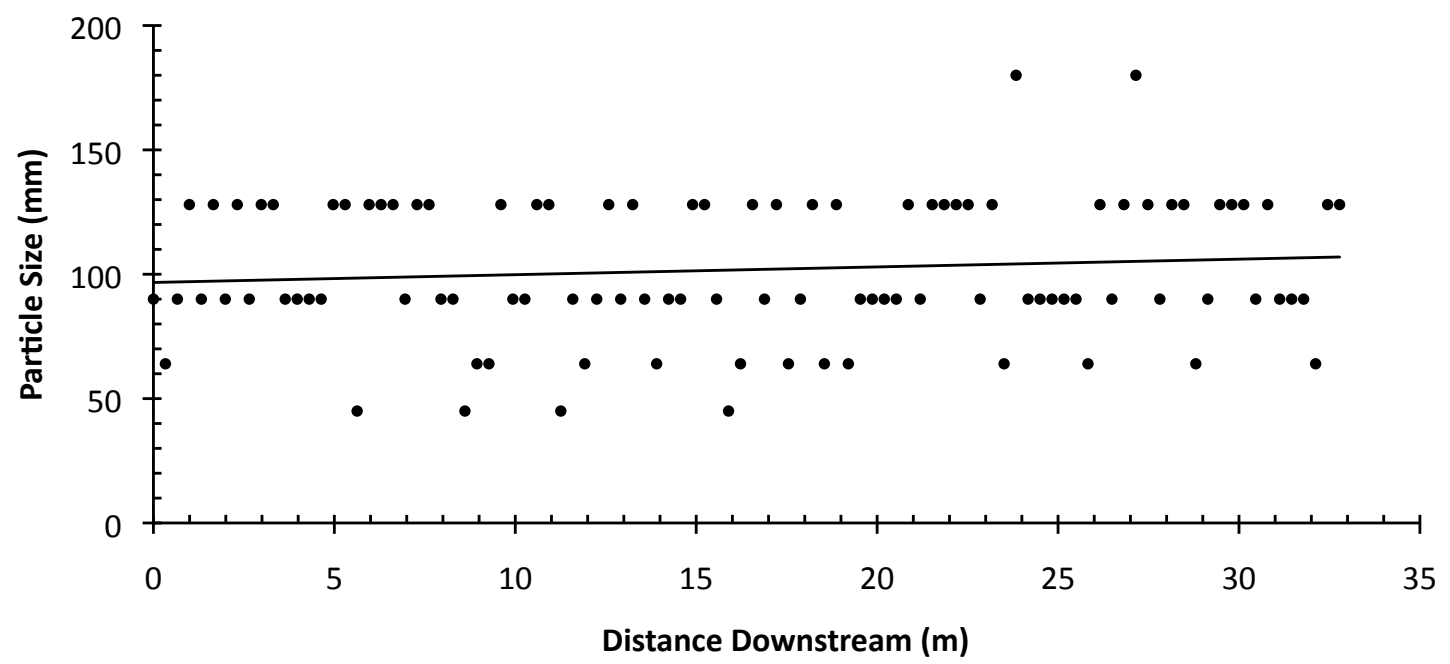

Figure 10. Surface grain size in the downstream direction on Bar 4 showing no statistically significant change. 


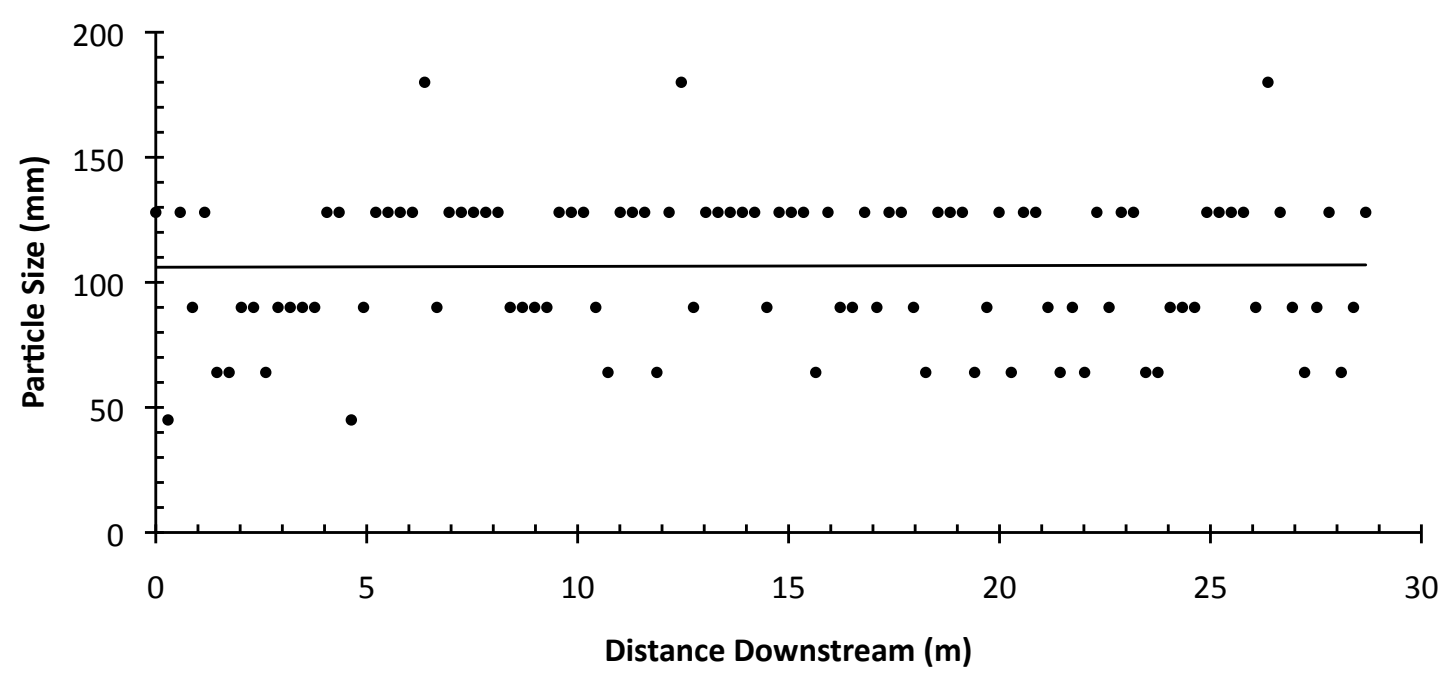

Figure 11. Surface grain size in the downstream direction on Bar 6 showing no statistically significant change.

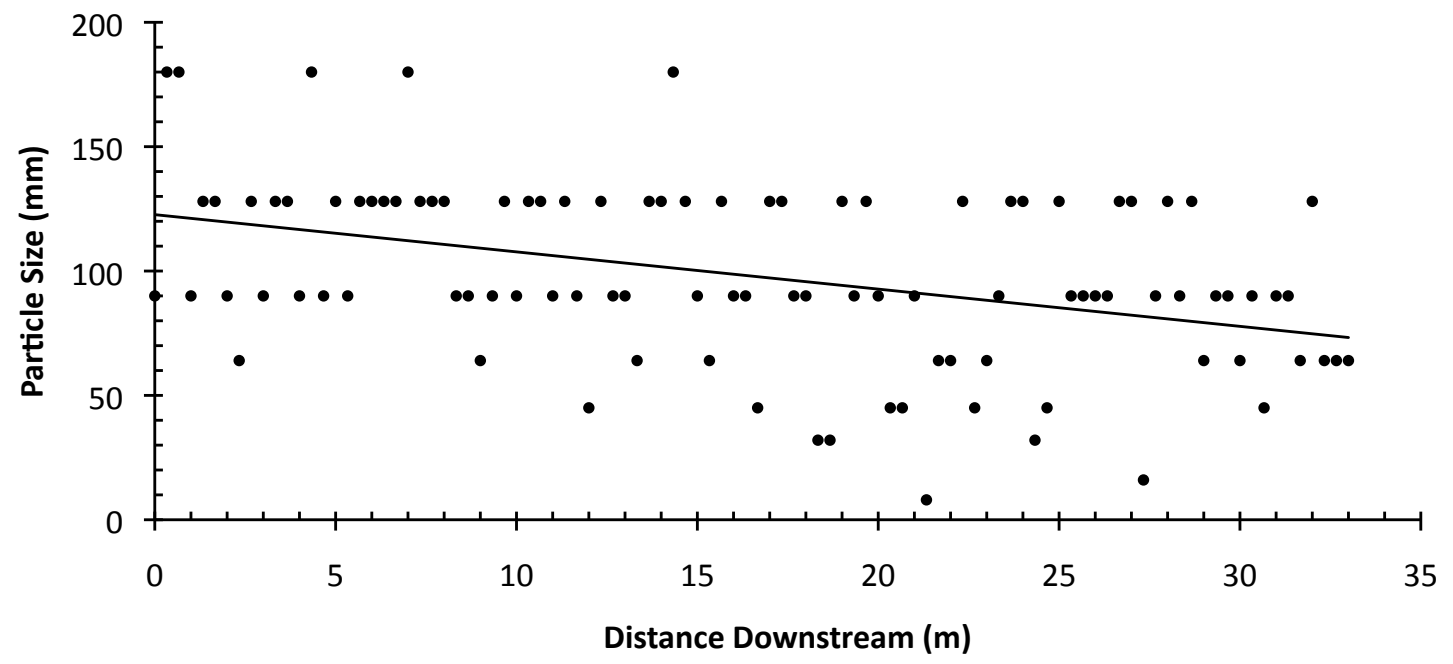

Figure 12. Surface grain size in the downstream direction on Bar 7 showing a statistically significant change. 


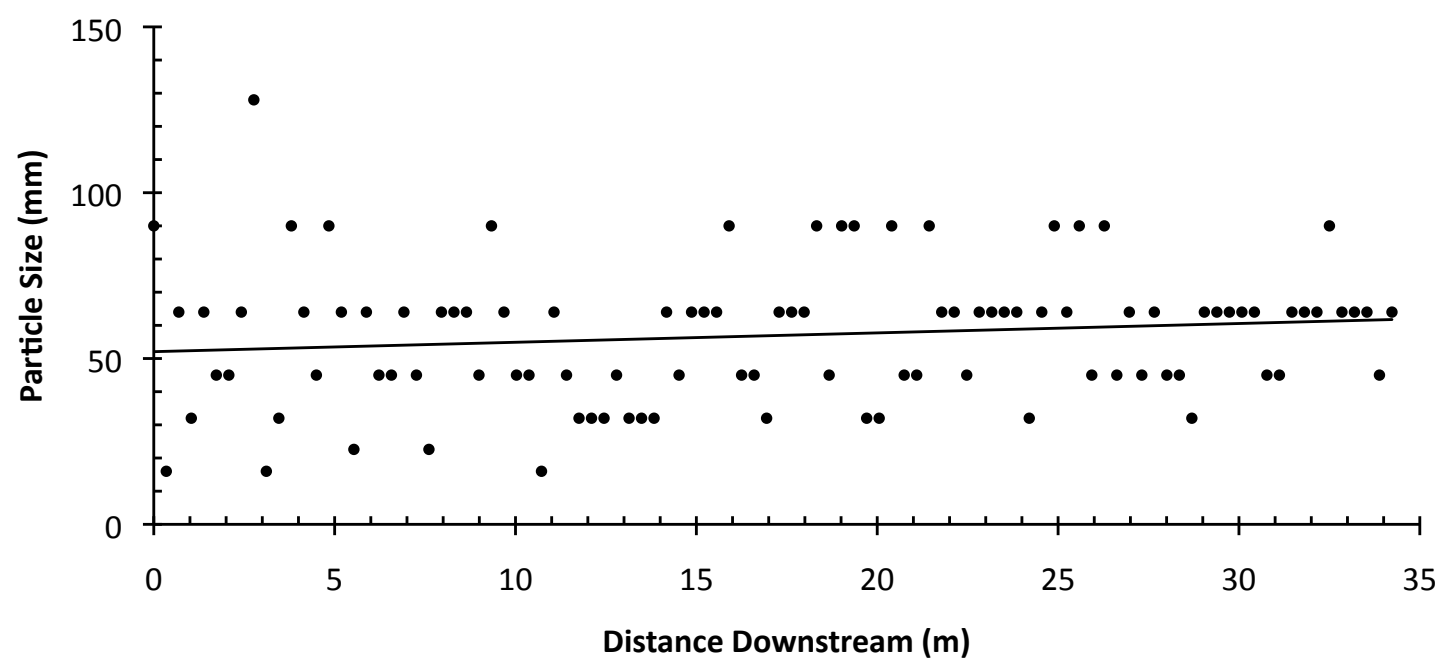

Figure 13. Surface grain size in the downstream direction on Bar 8 showing no statistically significant change. 
The FaSTMECH model predicted the highest bed shear stresses downstream of the apex of each bend. The lowest predicted bed shear stresses were along the margins of the wetted portion of the channel (Figure 14). The calculated $\tau_{\mathrm{cr}}$ and the $\tau_{b}$ predicted by FaSTMECH were unrelated at the inside, middle, and outside portions of each bend (Figures $15-18$ ). The modeled $\tau_{b}$ ranged from $1.45 \mathrm{~N} / \mathrm{m}^{2}$ at the outside of Bend 5 to $39.79 \mathrm{~N} / \mathrm{m}^{2}$ at the inside of Bend 3. The calculated $\tau_{\mathrm{cr}}$ ranged from a minimum of $18.99 \mathrm{~N} / \mathrm{m}^{2}$ at the middle of Bend 9 to a maximum of $41.64 \mathrm{~N} / \mathrm{m}^{2}$ at the outside of Bend 4 . At the inside of six of the ten bends, the modeled $\tau_{b}$ was lower than the calculated $\tau_{c r}$ (Figure 19). The differences between the modeled $\tau_{\mathrm{b}}$ and the calculated $\tau_{\mathrm{cr}}$ at the inside of these six bends ranged from $1.01 \mathrm{~N} / \mathrm{m}^{2}$ at Bend 5 to $21.1 \mathrm{~N} / \mathrm{m}^{2}$ at Bend 9. The modeled $\tau_{\mathrm{b}}$ was higher than the calculated $\tau_{\text {cr }}$ at the inside of Bends 2, 3, 4, and 8, with differences between the modeled $\tau_{\mathrm{b}}$ and the calculated $\tau_{\mathrm{cr}}$ ranging from $1.71 \mathrm{~N} / \mathrm{m}^{2}$ at Bend 4 to $18.77 \mathrm{~N} / \mathrm{m}^{2}$ at Bend 3. The modeled $\tau_{\mathrm{b}}$ was higher than the calculated $\tau_{\mathrm{cr}}$ in the middle of the channel at Bends 2, 4, and 8, with differences in modeled and calculated shear stresses ranging from $0.62 \mathrm{~N} / \mathrm{m}^{2}$ at Bend 4 to $20.21 \mathrm{~N} / \mathrm{m}^{2}$ at Bend 8 . FaSTMECH predicted bed shear stresses lower than the calculated critical shear stress in the middle of the channel at the other seven bends (Figure 20). Differences between the modeled $\tau_{\mathrm{b}}$ and the calculated $\tau_{\mathrm{cr}}$ at the middle of these seven bends ranged from $1.19 \mathrm{~N} / \mathrm{m}^{2}$ at Bend 6 to $10.91 \mathrm{~N} / \mathrm{m}^{2}$ at Bend 5 . 


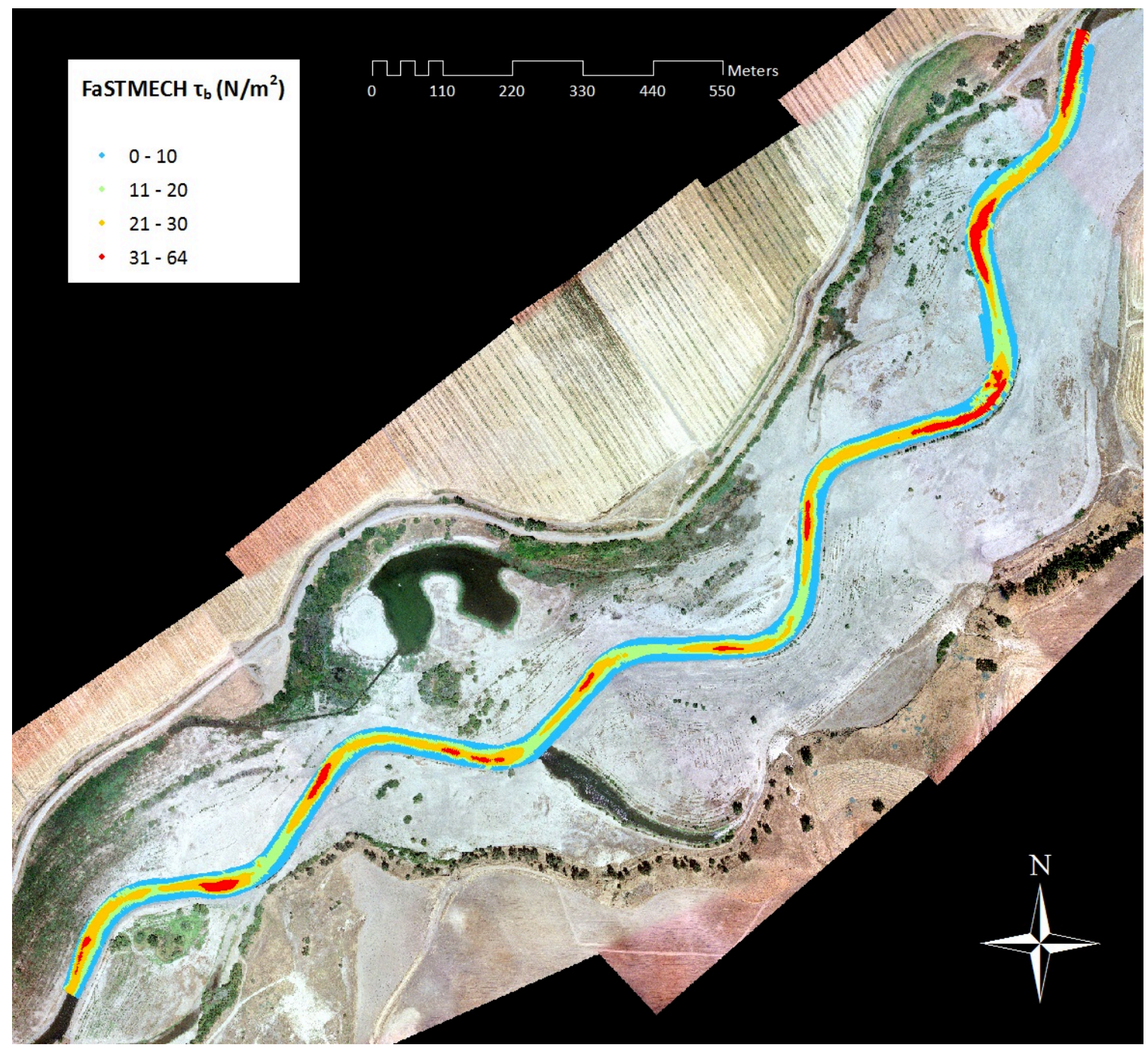

Figure 14. Spatial distribution of $\tau_{\mathrm{b}}$ predicted by the FaSTMECH model. 


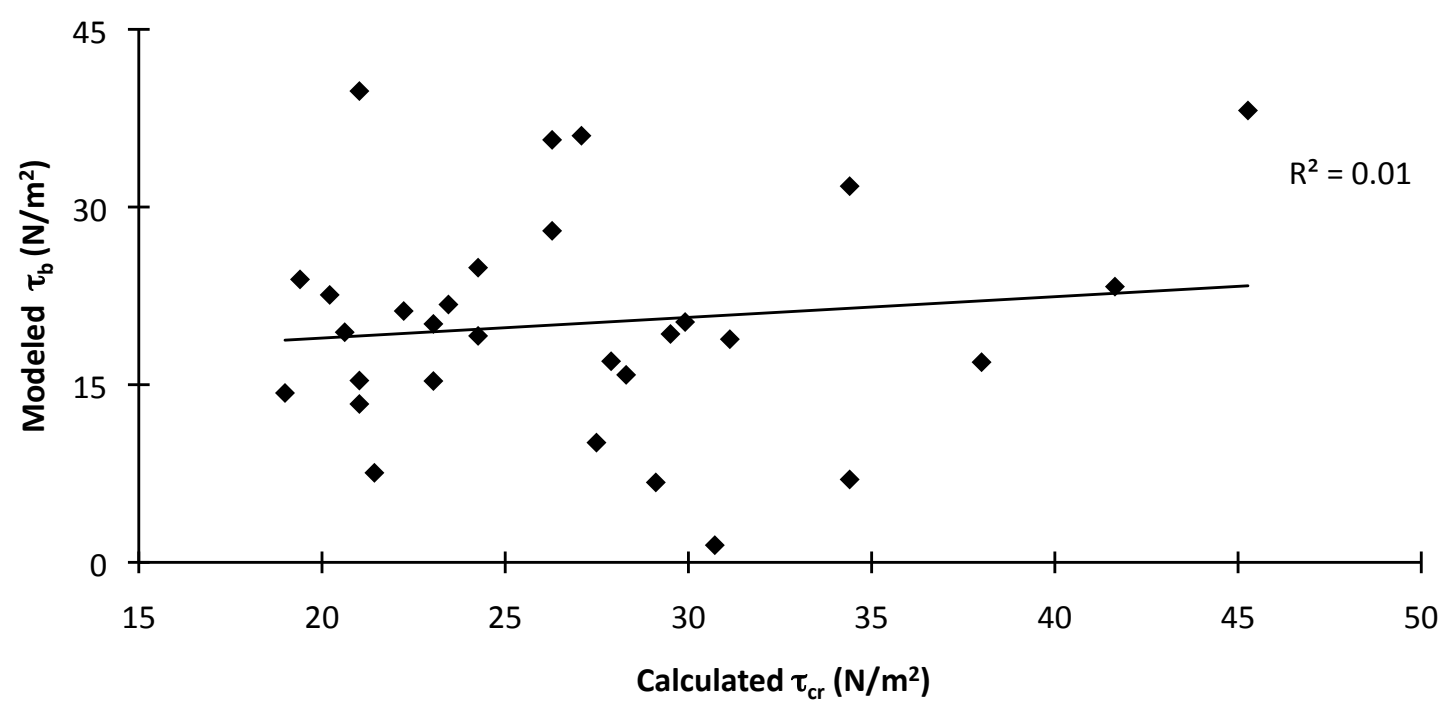

Figure 15 . Modeled $\tau_{\mathrm{b}}$ versus calculated $\tau_{\mathrm{cr}}$ at the bends in the study reach.

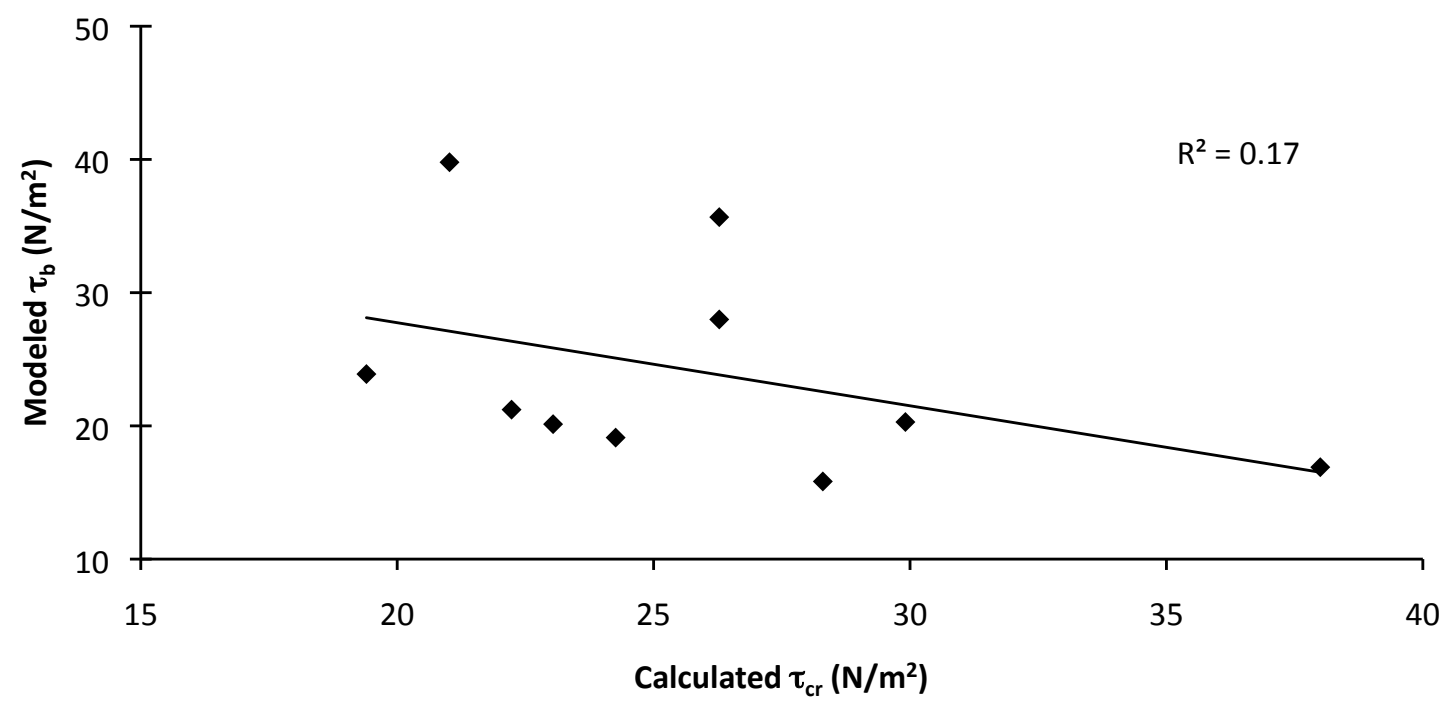

Figure 16. Modeled $\tau_{\mathrm{b}}$ versus calculated $\tau_{\mathrm{cr}}$ at the inside portions of the bends in the study reach. 


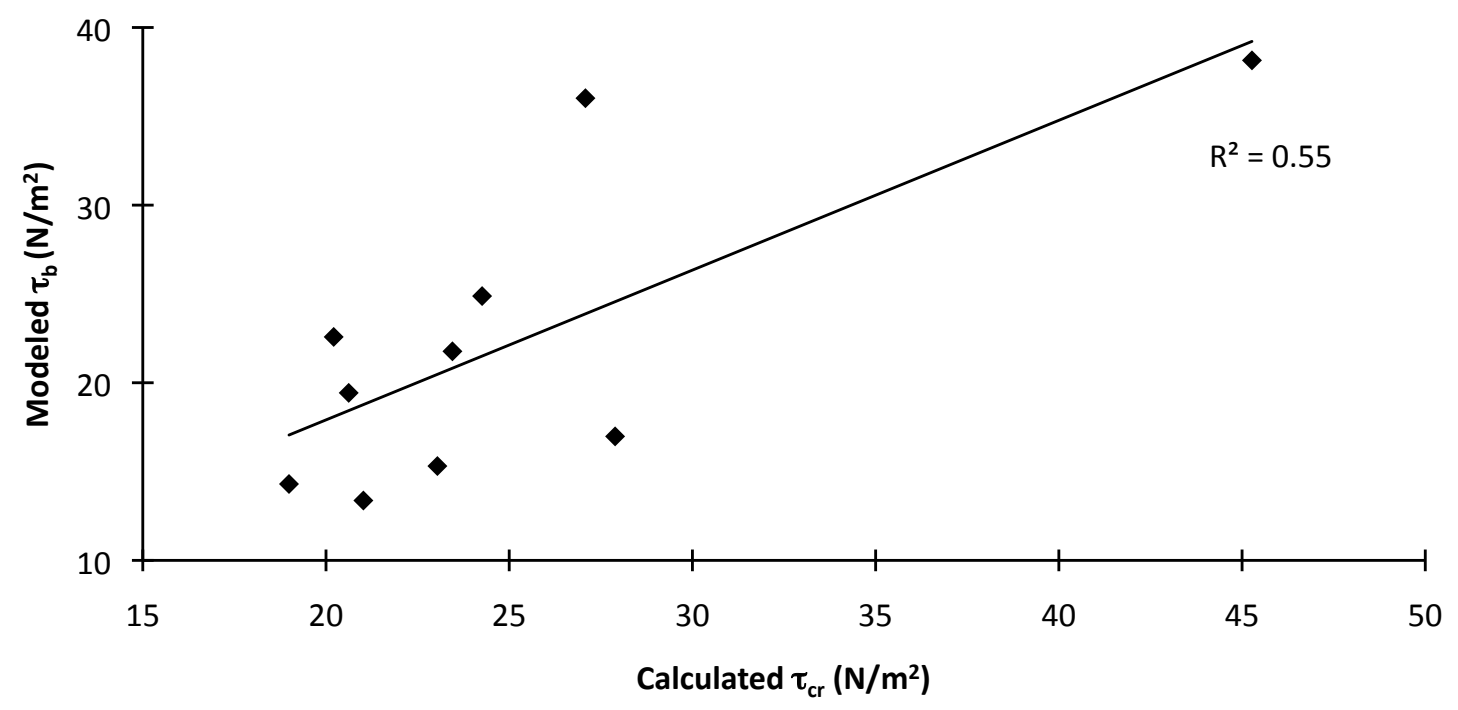

Figure 17. Modeled $\tau_{\mathrm{b}}$ versus calculated $\tau_{\mathrm{cr}}$ at the middle portions of the bends in the study reach.

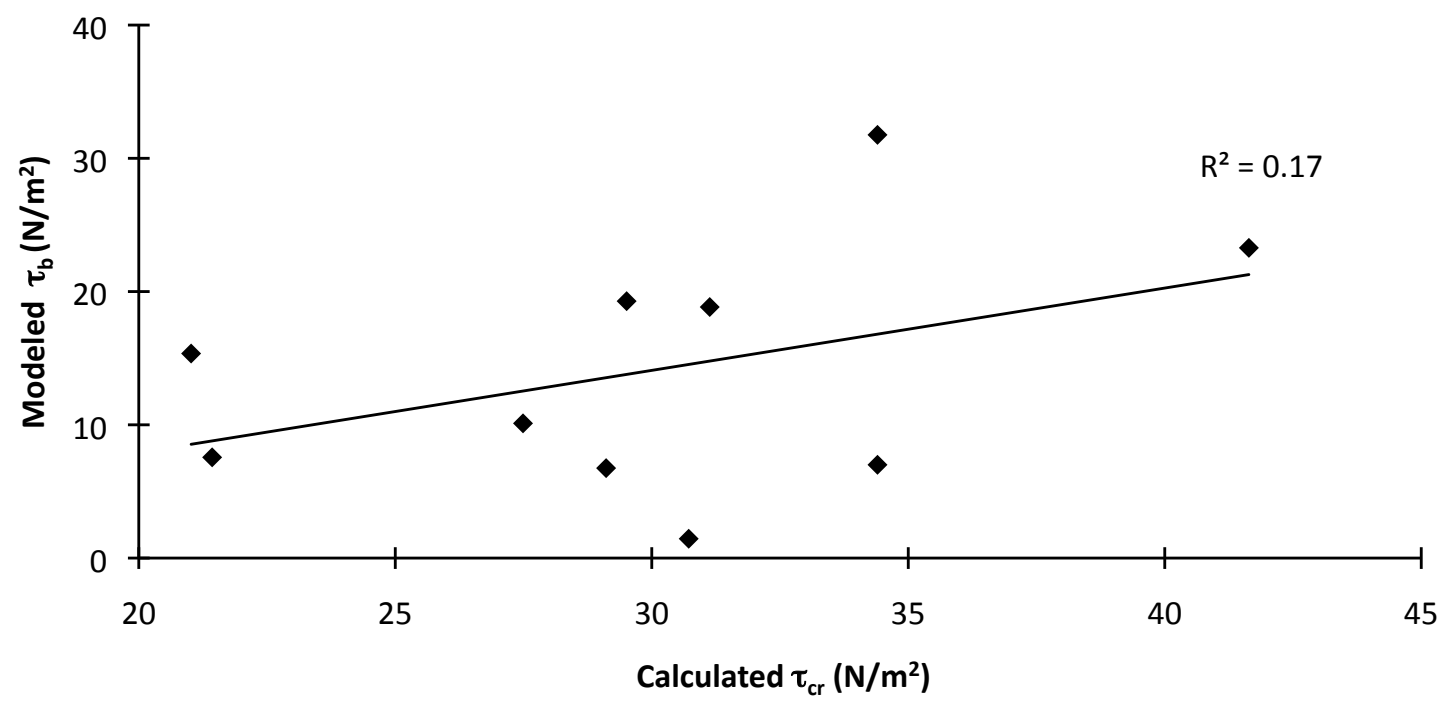

Figure 18. Modeled $\tau_{\mathrm{b}}$ versus calculated $\tau_{\mathrm{cr}}$ at the outside portions of the bends in the study reach. 


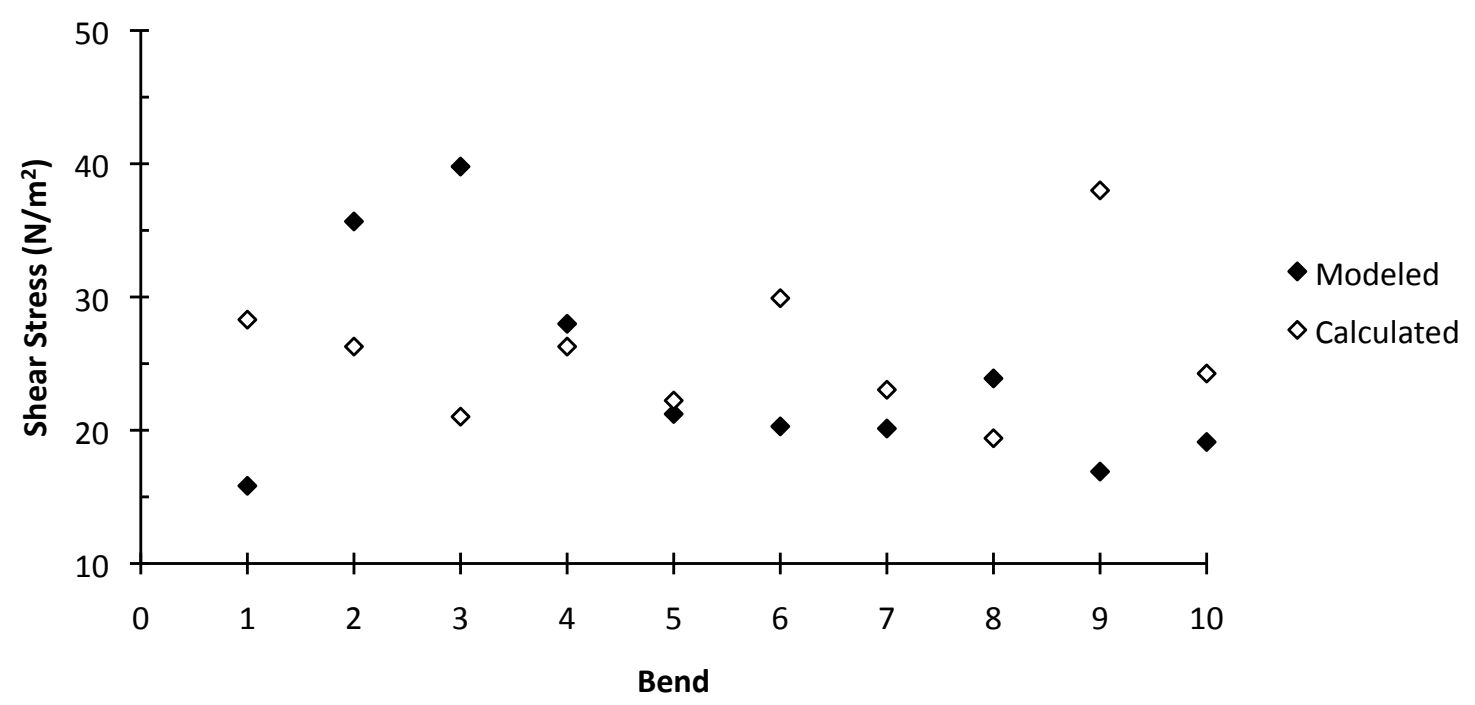

Figure 19. Modeled $\tau_{\mathrm{b}}$ and calculated $\tau_{\mathrm{cr}}$ at the inside portions of the bends in the study reach. $30 \%$ of the modeled values are within a $20 \%$ margin of their associated calculated values.

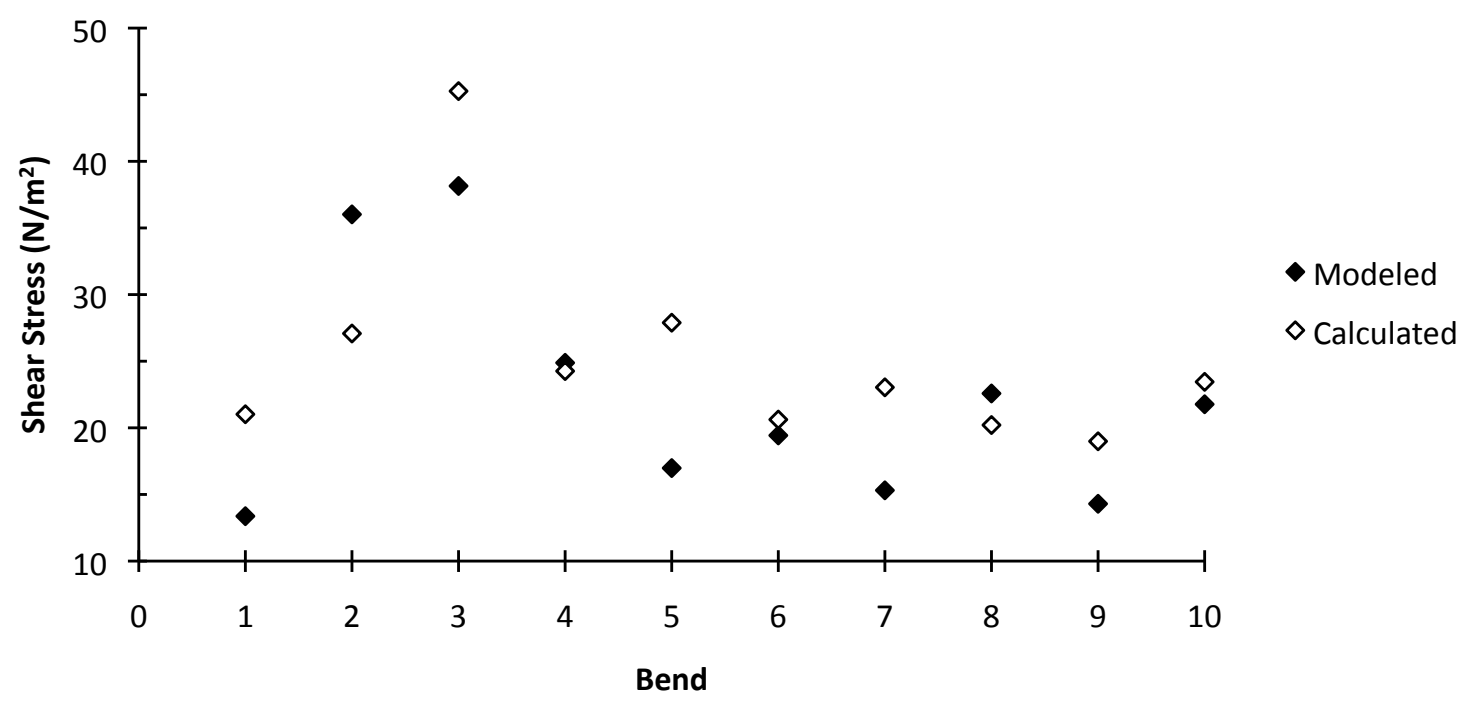

Figure 20. Modeled $\tau_{\mathrm{b}}$ and calculated $\tau_{\mathrm{cr}}$ at the middle portions of the bends in the study reach. $50 \%$ of the modeled values are within a $20 \%$ margin of their associated calculated values. 
The $\tau_{\mathrm{b}}$ predicted by the FaSTMECH model at the outside of each bend was lower than the calculated $\tau_{c r}$ at the same locations (Figure 21). The differences between the modeled $\tau_{\mathrm{b}}$ and the calculated $\tau_{\mathrm{cr}}$ at the outside of the bends ranged from 2.64 $\mathrm{N} / \mathrm{m}^{2}$ at Bend 2 to $29.27 \mathrm{~N} / \mathrm{m}^{2}$ at Bend 5 .

\section{DISCUSSION}

The bed material was organized spatially such that smaller particles were located on point bars at the inside of meander bends with larger particles in pools at the outside of meander bends. The observed spatial distribution of grain sizes was generally in agreement with past studies on bed surface grain size distribution in meandering rivers; however, the spatial distribution of grain sizes was reversed at Bends 6 and 9. At these bends, smaller particles were located at the outside of the bends with larger particles located at the inside of the bends. Rough hardpan was present at the outside portion of Bend 6. Smaller particles may have been deposited in topographically low areas like pockets in the hardpan, shielding them from the shear stress exerted by the flow while particles on the topographically higher areas of the hardpan were carried downstream. The thick vegetation in the outside half of the channel at Bend 9 obstructed flow, resulting in decreased shear stress. The decreased shear stress at the outside of Bend 9 may have caused smaller particles to be deposited in that area, resulting in a spatial distribution of grain sizes opposite that observed at the other seven bends. 


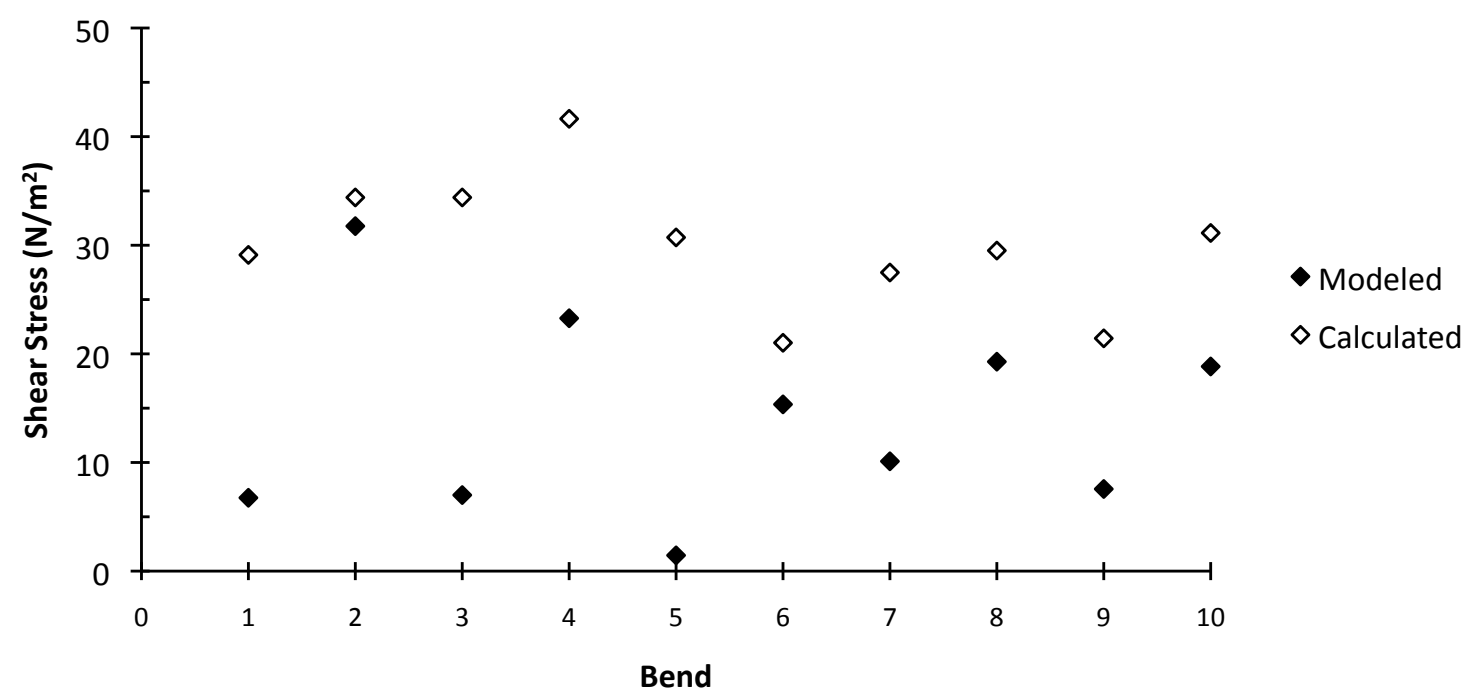

Figure 21. Modeled $\tau_{\mathrm{b}}$ and calculated $\tau_{\mathrm{cr}}$ at the outside portions of the bends in the study reach. $10 \%$ of the modeled values are within a $20 \%$ margin of their associated calculated values. 
Bend 9 has also experienced a significant amount of bank erosion. The bank-derived sediment, being finer than the $\mathrm{D}_{50}$ in the lower reach, may have contributed to the observed spatial distribution of grain sizes.

At Bend 3, the $\mathrm{D}_{50}$ in the middle portion of the channel was larger than the $\mathrm{D}_{50}$ at both the outside and inside portions of the bend. Smooth hardpan was present in the middle portion of the bend with only ten grains on the surface. Any grains that may have settled out of the flow or been deposited in the middle portion of Bend 3 were more likely to have been pushed downstream by the flow along the smooth hardpan than on the rough bed surface of the rest of the channel. Only particles large enough such that the gravitational force acting on them exceeded the shear stress exerted by the flow would remain in place, causing the median grain size to be larger at this location than at the outside and inside of the bend.

Temporally, there was no consistent pattern of coarsening or fining along the entire study reach, although the bed surface coarsened since reconstruction of the reach was completed in 2002. Harrison et al. (2015) found the $\mathrm{D}_{50}$ of the upper three bends in the reach to be $57 \mathrm{~mm}$ in 2012, $4.5 \mathrm{~mm}$ larger than the initial $\mathrm{D}_{50}$ in January 2002. The mean $D_{50}$ at the ten bends in study reach was $66.9 \mathrm{~mm}$ in April 2015 , significantly larger than the $D_{50}$ of the entire reach in 2012. Pebble count data from each year show that the bed surface $D_{50}$ of the entire study reach was not evolving in the same manner (Figure 5). The lack of pebble count data from each section in consecutive survey periods made it difficult to establish the presence of a consistent pattern of changes in bed surface $\mathrm{D}_{50}$. 
There did not appear to be significant temporal coarsening after the extended periods of overbank flow in Spring 2005 and Spring 2006, but the upper half of the reach did coarsen after the Spring 2011 flood event. The D D $_{0}$ increased from its initial size of $52.5 \mathrm{~mm}$ in 2002 to $57 \mathrm{~mm}$ in 2012 at the upper three bends (Harrison et al., 2011; Harrison et al., 2015). Coarse material may be supplied to the reach from the banks of the channel upstream of the study reach or from the floodplain during seasonal high flows and flood events. This coarse material may be deposited and act as bed armor; however, measurements of bed material beneath the surface layer were not taken during this study.

No apparent pattern of coarsening or fining on bar surfaces existed. Bars 3 and 7 displayed significant downstream changes in surface grain size with an increase on Bar 3 and a decrease on Bar 7. There was no significant change in surface grain size along the other five point bars.

The FaSTMECH model predicted bed shear stresses lower than the calculated critical shear stresses at the outside of each of the ten bends. The modeled $\tau_{\mathrm{b}}$ was lower than the calculated $\tau_{\mathrm{cr}}$ in the middle portion of seven of the ten bends. At the inside of the bends, the modeled $\tau_{\mathrm{b}}$ was lower than the calculated $\tau_{\mathrm{cr}}$ at six of the ten bends. While the modeled $\tau_{\mathrm{b}}$ was lower than the calculated $\tau_{\mathrm{cr}}$ at the outside of each bend, the difference between the modeled $\tau_{\mathrm{b}}$ and the calculated $\tau_{\mathrm{cr}}$ varied from bend to bend. The modeled $\tau_{\mathrm{b}}$ and the calculated $\tau_{\mathrm{cr}}$ were more closely related at the inside and middle portions of the bends than at the outside portions (Figures 19 21). The modeled $\tau_{\mathrm{b}}$ at the outside of Bend 2, the middle of Bends 3, 4, 6, 8, and 10, 
and the inside of Bends 4, 5, and 7 were within a $20 \%$ margin of the calculated shear stresses at those locations. Figures 19 and 20 show that there were similar downstream patterns in modeled $\tau_{\mathrm{b}}$ and calculated $\tau_{\mathrm{cr}}$ at the inside and middle portions of the bends. There was poor correlation between the modeled $\tau_{\mathrm{b}}$ and the calculated $\tau_{\mathrm{cr}}$ at the inside, middle, and outside of the bends (Figures $15-18$ ). These results are consistent with those of Nelson et al. (2015), who found no correlation between median bed surface grain size and bed shear stress. Their results, however, showed a strong correlation between bed shear stress and the median grain size of the bedload particles carried downstream. Sediment traps were not used in this study to capture the bedload being mobilized by the flow. Thus, measurement and analysis of bedload material is beyond the scope of this study.

The weak relationship between the modeled $\tau_{\mathrm{b}}$ and the calculated $\tau_{\mathrm{cr}}$ at the bends suggested that another mechanism such as helical secondary flows was responsible for the distinct sediment sorting patterns observed at the ten bends in the study reach. These secondary flows carried smaller particles upslope onto point bars while the force of gravity acting upon more massive particles caused them to roll downslope into pools at the outside of the bends (Bunte and Abt, 2001). Another factor that could have contributed to the weak relationship between modeled bed shear stress and median bed surface grain size is a diminished sediment supply caused by the dams upstream of the study reach. As sediment supply decreased, inactive zones of coarse material may have developed and expanded (Dietrich et al., 1989). These inactive zones of coarse material may not be 
mobilized until a period of high discharge can dislodge them and transport the material downstream. Fine material may be supplied to the channel, but it may be of such size that it is carried downstream in suspension during periods of average flow rather than being deposited on the bed surface. Although the Robinson Reach was constructed without bars or pools, these features formed over time by the same flow and sediment transport processes responsible for the observed grain size sorting.

The differences between the modeled $\tau_{\mathrm{b}}$ and the calculated $\tau_{\mathrm{cr}}$ may have been due to the greater width of the modeled bankfull flow relative to the actual flow in April 2015. Bed shear stress was modeled with a discharge of $42.5 \mathrm{~m}^{3} / \mathrm{s}$ while the discharge when pebble counts were conducted was $4.1 \mathrm{~m}^{3} / \mathrm{s}$ (California Data Exchange Center, cdec.water.ca.gov) (Figure 22). The April 2015 sampling points at the outside of the bends fell in zones of lower modeled bed shear stress than those at the inside of the bends, resulting in the modeled $\tau_{\mathrm{b}}$ being higher at the inside sampling points of the bends than at the outside sampling points (Figure 23).

\section{CONCLUSION}

Pebble counts at the bends in the study reach revealed a distinct spatial distribution of bed surface grain sizes. Larger particles were found in pools at the outside of bends while smaller particles were found at the inside of bends on point bars at eight of the ten bends. Two bends displayed a spatial distribution opposite that of the other eight bends. 


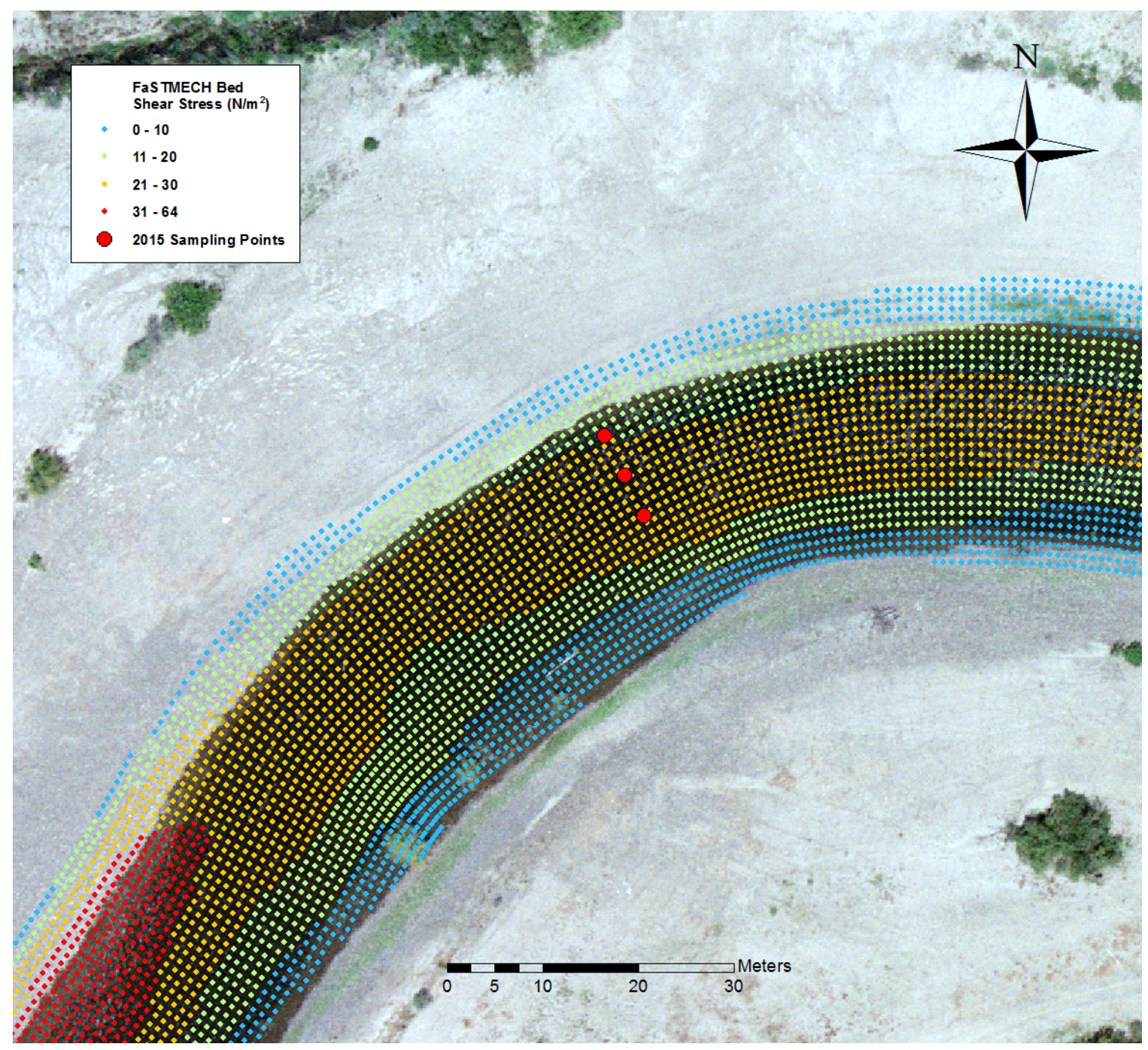

Figure 22. Close-up view of Bend 8 showing the positions of the April 2015 sampling points relative to the flow modeled by FaSTMECH. 


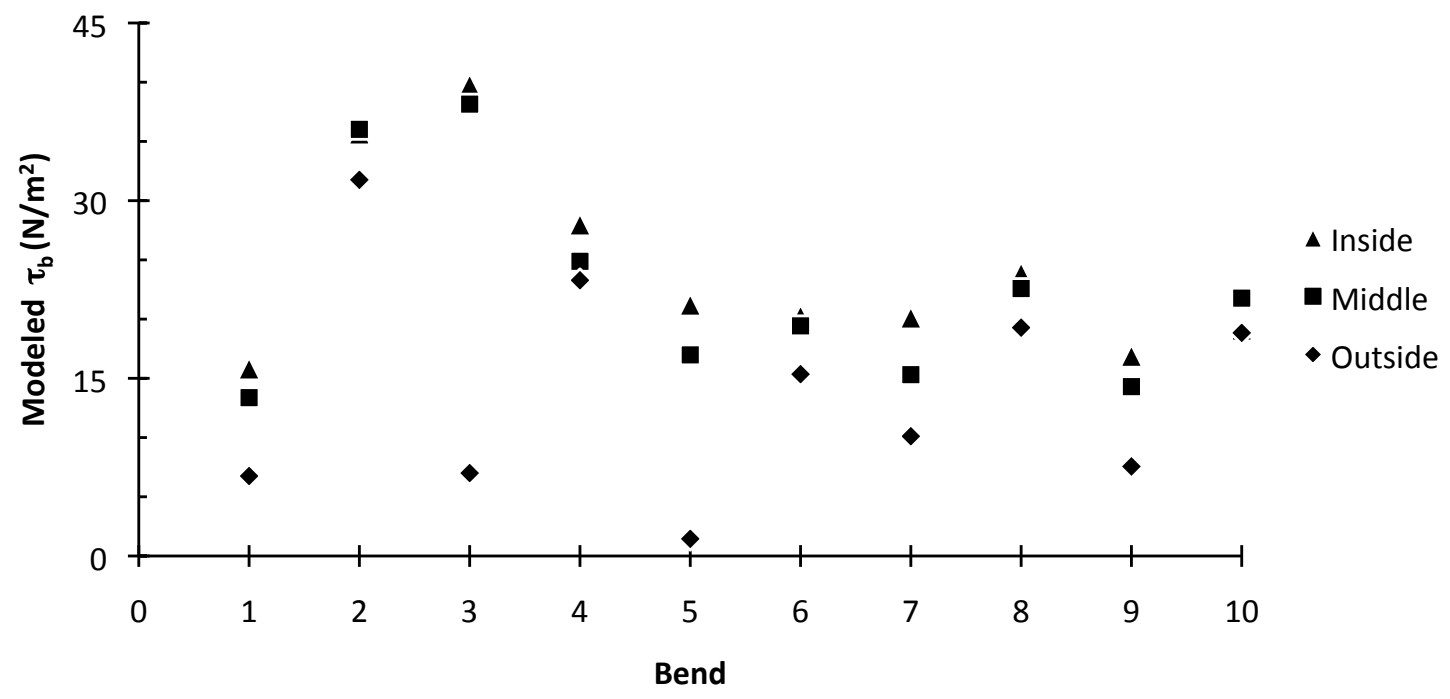

Figure 23. Modeled $\tau_{\mathrm{b}}$ at the inside, middle, and outside portions of the bends in the study reach. 
No consistent temporal pattern of coarsening or fining along the entire reach was found when pebble count data from April 2015 were compared to similar data from previous years; however, the bed surface has coarsened since completion of the reach in 2002. Harrison et al. (2015) note that the $D_{50}$ of the upper three bends of the study reach was $57 \mathrm{~mm}$ in June 2012 while the initial $\mathrm{D}_{50}$ in January 2002 was $52.5 \mathrm{~mm}$. The mean $\mathrm{D}_{50}$ at the bends was $66.9 \mathrm{~mm}$ in April 2015.

Regression analyses showed no clear pattern of coarsening or fining along the lengths of seven surveyed gravel bars. Only two of the seven bars showed a significant change in surface grain size in the downstream direction with grain size increasing on one bar and decreasing on the other.

Critical shear stresses calculated using median grain sizes from the inside, middle, and outside portions of the wetted channel were compared to bed shear stresses predicted by the FaSTMECH model. The modeled $\tau_{b}$ was higher than the calculated $\tau_{\text {cr }}$ in some portions of the bends, but lower in others. Similar patterns were seen in the modeled $\tau_{\mathrm{b}}$ and the calculated $\tau_{\mathrm{cr}}$ at the middle and inside portions of the bends. When plotted against one another, there was very little correlation between the modeled $\tau_{b}$ and the calculated $\tau_{c r}$. It is likely that secondary flows were responsible for the observed spatial distribution of grain sizes, with finer material being pushed up the slope of gravel bars while the force of gravity caused coarser particles to roll downslope into pools (Bunte and Abt, 2001). 


\section{REFERENCES}

Berenbrock, C., and Tranmer, A.W., 2008, Simulation of flow, sediment transport, and sediment mobility of the lower Coeur D'Alene River, Idaho: USGS Scientific Investigations Report 2008-5093.

Bernhardt, E. S., Palmer, M. A., Allan, J. D., Alexander, G., Barnas, K., and Brooks, S., 2005, Synthesizing US river restoration efforts: Science v. 308, p. 636-637.

Bernhardt, E.S., Sudduth, E. B., Palmer, M. A., Allan, J. D., Meyer, J. L., Alexander, G., Follastad-Shah, J., Hassett, B. Jenkinson, R., Lave, R., Rumps, J., and Pagano, L., 2007, Restoring rivers one reach at a time: Results from a survey of U.S. river restoration practitioners: Restoration Ecology, v. 15, no. 3, p. 482-493.

Buffington, J.M., and Montgomery, D.R., 1999, Effects of hydraulic roughness on surface textures of gravel-bed rivers: Water Resources Research, v. 35, p. 3507-3521.

Bunte, K., and Abt, S.R., 2001, Sampling surface and subsurface particle-size distributions in wadeable gravel- and cobble-bed streams for analysis in sediment transport, hydraulics, and streambed monitoring: USDA Forest Service, Rocky Mountain Research Station, Fort Collins, Colorado, General Technical Report RMRS-GTR-74, 428 p.

Bunte, K., Abt, S.R., Potyondy, J.P, and Swingle, K.W., 2009, Comparison of three pebble count protocols (EMAP, PIBO, and SFT) in two mountain gravel-bed streams: Journal of the American Water Resources Association, v. 45, p. 1209-1227.

California Department of Water Resources (CADWR), 2005, The Merced River Salmon Habitat Enhancement Project: Robinson Reach Phase III: CADWR: San Joaquin District, Fresno, CA, 159 p.

Dietrich, W. E., Kirchner, J. W., Ikeda, H., and Iseya, F., 1989, Sediment supply and the development of the coarse surface layer in gravel-bedded rivers: Nature, $v$. 340 , p. 215-217.

Gran, K. B., and Montgomery, D. R., 2005, Spatial and temporal patterns in fluvial recovery following volcanic eruptions: Channel response to basin-wide sediment loading at Mount Pinatubo, Philippines, Geological Society of America Bulletin, v. 117, no. 1-2, p. 195-211, doi: 10.1130/B25528.1. 
Gran, K., Montgomery, D. R., Sutherland, D. G., 2006, Channel bed evolution and sediment transport under declining sand inputs: Water Resources Research, v. 42, W10407, doi: 10.1029/2005WR004306.

Harrison, L. R., Legleiter, C. J., Wydzga, M. A., and Dunne, T., 2011, Channel dynamics and habitat development in a meandering, gravel bed river: Water Resources Research, v. 47, W04513. doi: 10.1029/2009WR008926.

Harrison, L. R., Dunne, T., and Fisher, G. B., 2015, Hydraulic and geomorphic processes in an overbank flood along a meandering, gravel-bed river: implications for chute formation: Earth Surface Processes and Landforms, v. 40, p. 1239-1253, doi: 10.1001/esp.3717.

Kondolf, G. M., 2006, River restoration and meanders: Ecology and Society, v. 11, no. 2, p. 42.

Lisle, T. E., Iseya, F., and Ikeda, H., 1993, Response of a channel with alternate bars to a decrease in supply of mixed-size bed load: A flume experiment: Water Resources Research, v. 29, no. 11, p. 3623-3629, doi: 10.1029/93WR01673.

Lisle, T. E., Nelson, J. M., Pilick, J., Madej, M. A., and Barkett, B. L., 2000, Variability of bed mobility in natural, gravel-bed channels and adjustments to sediment load at the local and reach scales: Water Resources Research, v. 36, no. 12, p. 3743- 3755, doi: 10.1029/2000WR900238.

Moyle, P. B., 2002, Salmon and Trout, Salmonidae - Chinook Salmon (Ocorhynchus tshawytscha): Inland Fishes of California: Los Angeles, California, University of California Press, p. 251-263.

Moyle, P. B., Yoshiyama, R. M., Williams, J. E., and Wikramanayake, E. D., 1995, Fish Species of Special Concern in California, Second Edition: Final Report for Contract No. 2128IF, California Department of Fish and Wildlife, Inland Fisheries Division.

Nelson, P. A., Venditti, J. G., Dietrich, W. E., Kirchner, J. W., Ikeda, H., Iseya, F., and Sklar, L., 2009, Response of bed surface patchiness to reductions in sediment supply: Journal of Geophysical Research, vol. 114, F02005, doi: 10.1029/2008JF001144.

Nelson, P. A., McDonald, R. R., Nelson, J. M., and Dietrich, W. E., 2015, Coevolution of bed surface patchiness and channel morphology: 1. Mechanisms of forced patch formation: Journal of Geophysical Research: Earth Surface, v. 129, doi: 10.1002/2014JF003428. 
Pittman, E.D., and Ovenshine, A.T., 1968, Pebble morphology in the Merced River (California): Sedimentary Geology, v. 2, p. 125-140.

Powell, D.M., 1998, Patterns and processes of sediment sorting in gravel-bed rivers: Progress in Physical Geography, v. 22, p. 1-32.

Raleigh, R. F., Miller, W. J., and Nelson, P. C., 1986, Habitat suitability index models and instream flow suitability curves: Chinook Salmon: United States Fish and Wildlife Service Biological Report 82 (10.122).

Trush, W. J., McBain, S.M., and Leopold, L.B., 2000, Attributes of an alluvial river and their relation to water policy and management: Proc. Natl. Acad. Sci. U. S. A., 97, 11,858-11,863, doi: 10.1073/pnas.97.22.11858.

Utz, R.M., Zeug, S.C., and Cardinale, B.J., 2012, Juvenile Chinook salmon, Oncorhynchus tshawystscha, growth and diet in riverine habitat engineered to improve conditions for spawning: Fisheries Management and Ecology, p. 114.

Whiting, P. J., Dietrich, W. E., Leopold, L. B., Drake, T. G., and Shreve, R. L., 1988, Bedload sheets in heterogeneous sediment: Geology, v. 16, p. 105-108.

Wolman, M.G., 1954, A method of sampling coarse river-bed material: Transactions, American Geophysical Union, v. 35, p. 951-956. 


\section{Appendix \\ Pebble Count Data}

\begin{tabular}{|c|c|c|c|}
\hline \multicolumn{2}{|l|}{ River } & \multicolumn{2}{|l|}{ Merced } \\
\hline \multicolumn{2}{|l|}{ Location } & \multicolumn{2}{|l|}{ Robinson Reach } \\
\hline \multicolumn{2}{|l|}{ Date } & \multicolumn{2}{|l|}{ April 2015} \\
\hline \multicolumn{2}{|c|}{ Observer } & \multicolumn{2}{|l|}{ Emerson } \\
\hline \multicolumn{2}{|c|}{ Bend 1 Inside } & \multicolumn{2}{|c|}{ Bend 1 Middle } \\
\hline \multicolumn{2}{|c|}{$\mathrm{D}_{50}=70 \mathrm{~mm}$} & \multicolumn{2}{|c|}{$\mathrm{D}_{50}=52 \mathrm{~mm}$} \\
\hline Size $(\mathrm{mm})$ & $\%$ Finer & Size $(\mathrm{mm})$ & $\%$ Finer \\
\hline 512 & 100.0 & 512 & 100.0 \\
\hline 362 & 100.0 & 362 & 100.0 \\
\hline 256 & 100.0 & 256 & 100.0 \\
\hline 180 & 96.0 & 180 & 100.0 \\
\hline 128 & 78.0 & 128 & 93.0 \\
\hline 90 & 41.0 & 90 & 74.0 \\
\hline 64 & 16.0 & 64 & 37.0 \\
\hline 45 & 9.0 & 45 & 20.0 \\
\hline 32 & 2.0 & 32 & 7.0 \\
\hline 22.6 & 1.0 & 22.6 & 1.0 \\
\hline 16 & 0.0 & 16 & 0.0 \\
\hline 11.3 & 0.0 & 11.3 & 0.0 \\
\hline 8 & 0.0 & 8 & 0.0 \\
\hline
\end{tabular}

\begin{tabular}{|c|c|}
\hline \multicolumn{2}{|c|}{ Bend 1 Outside } \\
\hline \multicolumn{2}{|c|}{$\mathrm{D}_{50}=72 \mathrm{~mm}$} \\
\hline Size $(\mathrm{mm})$ & \% Finer \\
\hline 512 & 100.0 \\
\hline 362 & 100.0 \\
\hline 256 & 100.0 \\
\hline 180 & 90.0 \\
\hline 128 & 67.0 \\
\hline 90 & 43.0 \\
\hline 64 & 26.0 \\
\hline 45 & 7.0 \\
\hline 32 & 1.0 \\
\hline 22.6 & 0.0 \\
\hline 16 & 0.0 \\
\hline 11.3 & 0.0 \\
\hline 8 & 0.0 \\
\hline
\end{tabular}




\begin{tabular}{|l|c|}
\hline River & Merced \\
\hline Location & Robinson Reach \\
\hline Date & April 2015 \\
\hline Observer & Emerson \\
\hline
\end{tabular}

\begin{tabular}{|c|c|}
\hline \multicolumn{2}{|c|}{ Bend 2 Inside } \\
\hline \multicolumn{2}{|c|}{$D_{50}=65 \mathrm{~mm}$} \\
\hline Size $(\mathrm{mm})$ & \% Finer \\
\hline 512 & 100.0 \\
\hline 362 & 100.0 \\
\hline 256 & 100.0 \\
\hline 180 & 92.0 \\
\hline 128 & 73.0 \\
\hline 90 & 49.0 \\
\hline 64 & 26.0 \\
\hline 45 & 10.0 \\
\hline 32 & 4.0 \\
\hline 22.6 & 0.0 \\
\hline 16 & 0.0 \\
\hline 11.3 & 0.0 \\
\hline 8 & 0.0 \\
\hline
\end{tabular}

\begin{tabular}{|c|c|}
\hline \multicolumn{2}{|c|}{ Bend 2 Middle } \\
\hline \multicolumn{2}{|c|}{$\mathrm{D}_{50}=67 \mathrm{~mm}$} \\
\hline Size $(\mathrm{mm})$ & \% Finer \\
\hline 512 & 100.0 \\
\hline 362 & 100.0 \\
\hline 256 & 100.0 \\
\hline 180 & 94.0 \\
\hline 128 & 79.0 \\
\hline 90 & 46.0 \\
\hline 64 & 20.0 \\
\hline 45 & 8.0 \\
\hline 32 & 1.0 \\
\hline 22.6 & 0.0 \\
\hline 16 & 0.0 \\
\hline 11.3 & 0.0 \\
\hline 8 & 0.0 \\
\hline
\end{tabular}

\begin{tabular}{|c|c|}
\hline \multicolumn{2}{|c|}{ Bend 2 Outside } \\
\hline \multicolumn{2}{|c|}{$D_{50}=85 \mathrm{~mm}$} \\
\hline Size $(\mathrm{mm})$ & $\%$ Finer \\
\hline 512 & 100.0 \\
\hline 362 & 95.0 \\
\hline 256 & 92.0 \\
\hline 180 & 83.0 \\
\hline 128 & 54.0 \\
\hline 90 & 35.0 \\
\hline 64 & 17.0 \\
\hline 45 & 9.0 \\
\hline 32 & 5.0 \\
\hline 22.6 & 2.0 \\
\hline 16 & 0.0 \\
\hline 11.3 & 0.0 \\
\hline 8 & 0.0 \\
\hline
\end{tabular}




\begin{tabular}{|l|c|}
\hline River & Merced \\
\hline Location & Robinson Reach \\
\hline Date & April 2015 \\
\hline Observer & Emerson \\
\hline
\end{tabular}

\begin{tabular}{|c|c|}
\hline \multicolumn{2}{|c|}{ Bend 3 Inside } \\
\hline \multicolumn{2}{|c|}{$D_{50}=52 \mathrm{~mm}$} \\
\hline Size $(\mathrm{mm})$ & \% Finer \\
\hline 512 & 100.0 \\
\hline 362 & 100.0 \\
\hline 256 & 100.0 \\
\hline 180 & 99.0 \\
\hline 128 & 88.0 \\
\hline 90 & 67.0 \\
\hline 64 & 41.0 \\
\hline 45 & 17.0 \\
\hline 32 & 2.0 \\
\hline 22.6 & 0.0 \\
\hline 16 & 0.0 \\
\hline 11.3 & 0.0 \\
\hline 8 & 0.0 \\
\hline
\end{tabular}

\begin{tabular}{|c|c|}
\hline \multicolumn{2}{|c|}{ Bend 3 Middle } \\
\hline $\mathrm{D}_{50}=112 \mathrm{~mm}$ \\
\hline Size $(\mathrm{mm})$ & \% Finer \\
\hline 512 & 100.0 \\
\hline 362 & 90.0 \\
\hline 256 & 80.0 \\
\hline 180 & 60.0 \\
\hline 128 & 50.0 \\
\hline 90 & 20.0 \\
\hline 64 & 10.0 \\
\hline 45 & 0.0 \\
\hline 32 & 0.0 \\
\hline 22.6 & 0.0 \\
\hline 16 & 0.0 \\
\hline 11.3 & 0.0 \\
\hline 8 & 0.0 \\
\hline
\end{tabular}

\begin{tabular}{|c|c|}
\hline \multicolumn{2}{|c|}{ Bend 3 Outside } \\
\hline \multicolumn{2}{|c|}{$D_{50}=85 \mathrm{~mm}$} \\
\hline Size $(\mathrm{mm})$ & $\%$ Finer \\
\hline 512 & 100.0 \\
\hline 362 & 95.0 \\
\hline 256 & 92.0 \\
\hline 180 & 83.0 \\
\hline 128 & 54.0 \\
\hline 90 & 35.0 \\
\hline 64 & 17.0 \\
\hline 45 & 9.0 \\
\hline 32 & 5.0 \\
\hline 22.6 & 2.0 \\
\hline 16 & 0.0 \\
\hline 11.3 & 0.0 \\
\hline 8 & 0.0 \\
\hline
\end{tabular}




\begin{tabular}{|l|c|}
\hline River & Merced \\
\hline Location & Robinson Reach \\
\hline Date & April 2015 \\
\hline Observer & Emerson \\
\hline
\end{tabular}

\begin{tabular}{|c|c|}
\hline \multicolumn{2}{|c|}{ Bend 4 Inside } \\
\hline \multicolumn{2}{|c|}{$D_{50}=65 \mathrm{~mm}$} \\
\hline Size $(\mathrm{mm})$ & \% Finer \\
\hline 512 & 100.0 \\
\hline 362 & 100.0 \\
\hline 256 & 100.0 \\
\hline 180 & 98.0 \\
\hline 128 & 88.0 \\
\hline 90 & 49.0 \\
\hline 64 & 28.0 \\
\hline 45 & 14.0 \\
\hline 32 & 5.0 \\
\hline 22.6 & 3.0 \\
\hline 16 & 0.0 \\
\hline 11 & 0.0 \\
\hline 8 & 0.0 \\
\hline
\end{tabular}

\begin{tabular}{|c|c|}
\hline \multicolumn{2}{|c|}{ Bend 4 Middle } \\
\hline \multicolumn{2}{|c|}{$\mathrm{D}_{50}=60 \mathrm{~mm}$} \\
\hline Size $(\mathrm{mm})$ & \% Finer \\
\hline 512 & 100.0 \\
\hline 362 & 99.0 \\
\hline 256 & 98.0 \\
\hline 180 & 95.0 \\
\hline 128 & 82.0 \\
\hline 90 & 56.0 \\
\hline 64 & 27.0 \\
\hline 45 & 14.0 \\
\hline 32 & 5.0 \\
\hline 22.6 & 0.0 \\
\hline 16 & 0.0 \\
\hline 11 & 0.0 \\
\hline 8 & 0.0 \\
\hline
\end{tabular}

\begin{tabular}{|c|c|}
\hline \multicolumn{2}{|c|}{ Bend 4 Outside } \\
\hline \multicolumn{2}{|c|}{$D_{50}=103 \mathrm{~mm}$} \\
\hline Size $(\mathrm{mm})$ & $\%$ Finer \\
\hline 512 & 100.0 \\
\hline 362 & 100.0 \\
\hline 256 & 96.0 \\
\hline 180 & 74.0 \\
\hline 128 & 38.0 \\
\hline 90 & 25.0 \\
\hline 64 & 16.0 \\
\hline 45 & 10.0 \\
\hline 32 & 7.0 \\
\hline 22.6 & 4.0 \\
\hline 16 & 1.0 \\
\hline 11 & 1.0 \\
\hline 8 & 0.0 \\
\hline
\end{tabular}




\begin{tabular}{|l|c|}
\hline River & Merced \\
\hline Location & Robinson Reach \\
\hline Date & April 2015 \\
\hline Observer & Emerson \\
\hline
\end{tabular}

\begin{tabular}{|c|c|}
\hline \multicolumn{2}{|c|}{ Bend 5 Inside } \\
\hline \multicolumn{2}{|c|}{$D_{50}=55 \mathrm{~mm}$} \\
\hline Size $(\mathrm{mm})$ & \% Finer \\
\hline 512 & 100.0 \\
\hline 362 & 100.0 \\
\hline 256 & 100.0 \\
\hline 180 & 100.0 \\
\hline 128 & 90.0 \\
\hline 90 & 62.0 \\
\hline 64 & 37.0 \\
\hline 45 & 23.0 \\
\hline 32 & 12.0 \\
\hline 22.6 & 5.0 \\
\hline 16 & 0.0 \\
\hline 11.3 & 0.0 \\
\hline 8 & 0.0 \\
\hline
\end{tabular}

\begin{tabular}{|c|c|}
\hline \multicolumn{2}{|c|}{ Bend 5 Middle } \\
\hline $\mathrm{D}_{50}=69 \mathrm{~mm}$ \\
\hline Size $(\mathrm{mm})$ & \% Finer \\
\hline 512 & 100.0 \\
\hline 362 & 100.0 \\
\hline 256 & 99.0 \\
\hline 180 & 86.0 \\
\hline 128 & 70.0 \\
\hline 90 & 45.0 \\
\hline 64 & 23.0 \\
\hline 45 & 10.0 \\
\hline 32 & 4.0 \\
\hline 22.6 & 2.0 \\
\hline 16 & 0.0 \\
\hline 11.3 & 0.0 \\
\hline 8 & 0.0 \\
\hline
\end{tabular}

\begin{tabular}{|c|c|}
\hline \multicolumn{2}{|c|}{ Bend 5 Outside } \\
\hline \multicolumn{2}{|c|}{$D_{50}=76 \mathrm{~mm}$} \\
\hline Size $(\mathrm{mm})$ & $\%$ Finer \\
\hline 512 & 100.0 \\
\hline 362 & 100.0 \\
\hline 256 & 97.0 \\
\hline 180 & 89.0 \\
\hline 128 & 62.0 \\
\hline 90 & 40.0 \\
\hline 64 & 26.0 \\
\hline 45 & 12.0 \\
\hline 32 & 6.0 \\
\hline 22.6 & 2.0 \\
\hline 16 & 1.0 \\
\hline 11.3 & 1.0 \\
\hline 8 & 0.0 \\
\hline
\end{tabular}




\begin{tabular}{|l|c|}
\hline River & Merced \\
\hline Location & Robinson Reach \\
\hline Date & April 2015 \\
\hline Observer & Emerson \\
\hline
\end{tabular}

\begin{tabular}{|c|c|}
\hline \multicolumn{2}{|c|}{ Bend 6 Inside } \\
\hline \multicolumn{2}{|c|}{$\mathrm{D}_{50}=74 \mathrm{~mm}$} \\
\hline Size $(\mathrm{mm})$ & \% Finer \\
\hline 512 & 100.0 \\
\hline 362 & 100.0 \\
\hline 256 & 100.0 \\
\hline 180 & 100.0 \\
\hline 128 & 68.0 \\
\hline 90 & 39.0 \\
\hline 64 & 15.0 \\
\hline 45 & 12.0 \\
\hline 32 & 3.0 \\
\hline 22.6 & 0.0 \\
\hline 16 & 0.0 \\
\hline 11.3 & 0.0 \\
\hline 8 & 0.0 \\
\hline
\end{tabular}

\begin{tabular}{|c|c|}
\hline \multicolumn{2}{|c|}{ Bend 6 Middle } \\
\hline $\mathrm{D}_{50}=51 \mathrm{~mm}$ \\
\hline Size $(\mathrm{mm})$ & \% Finer \\
\hline 512 & 100.0 \\
\hline 362 & 100.0 \\
\hline 256 & 100.0 \\
\hline 180 & 100.0 \\
\hline 128 & 93.0 \\
\hline 90 & 66.0 \\
\hline 64 & 43.0 \\
\hline 45 & 29.0 \\
\hline 32 & 22.0 \\
\hline 22.6 & 9.0 \\
\hline 16 & 1.0 \\
\hline 11.3 & 1.0 \\
\hline 8 & 0.0 \\
\hline
\end{tabular}

\begin{tabular}{|c|c|}
\hline \multicolumn{2}{|c|}{ Bend 6 Outside } \\
\hline \multicolumn{2}{|c|}{$\mathrm{D}_{50}=52 \mathrm{~mm}$} \\
\hline Size $(\mathrm{mm})$ & $\%$ Finer \\
\hline 512 & 100.0 \\
\hline 362 & 100.0 \\
\hline 256 & 100.0 \\
\hline 180 & 94.0 \\
\hline 128 & 88.0 \\
\hline 90 & 65.0 \\
\hline 64 & 42.0 \\
\hline 45 & 27.0 \\
\hline 32 & 17.0 \\
\hline 22.6 & 15.0 \\
\hline 16 & 3.0 \\
\hline 11.3 & 3.0 \\
\hline 8 & 0.0 \\
\hline
\end{tabular}




\begin{tabular}{|l|c|}
\hline River & Merced \\
\hline Location & Robinson Reach \\
\hline Date & April 2015 \\
\hline Observer & Emerson \\
\hline
\end{tabular}

\begin{tabular}{|c|c|}
\hline \multicolumn{2}{|c|}{ Bend 7 Inside } \\
\hline \multicolumn{2}{|c|}{$\mathrm{D}_{50}=57 \mathrm{~mm}$} \\
\hline Size $(\mathrm{mm})$ & \% Finer \\
\hline 512 & 100.0 \\
\hline 362 & 100.0 \\
\hline 256 & 100.0 \\
\hline 180 & 100.0 \\
\hline 128 & 88.0 \\
\hline 90 & 62.0 \\
\hline 64 & 29.0 \\
\hline 45 & 19.0 \\
\hline 32 & 15.0 \\
\hline 22.6 & 11.0 \\
\hline 16 & 1.0 \\
\hline 11.3 & 1.0 \\
\hline 8 & 0.0 \\
\hline
\end{tabular}

\begin{tabular}{|c|c|}
\hline \multicolumn{2}{|c|}{ Bend 7 Middle } \\
\hline \multicolumn{2}{|c|}{$\mathrm{D}_{50}=57 \mathrm{~mm}$} \\
\hline Size $(\mathrm{mm})$ & \% Finer \\
\hline 512 & 100.0 \\
\hline 362 & 100.0 \\
\hline 256 & 100.0 \\
\hline 180 & 100.0 \\
\hline 128 & 90.0 \\
\hline 90 & 61.0 \\
\hline 64 & 33.0 \\
\hline 45 & 18.0 \\
\hline 32 & 11.0 \\
\hline 22.6 & 8.0 \\
\hline 16 & 0.0 \\
\hline 11.3 & 0.0 \\
\hline 8 & 0.0 \\
\hline
\end{tabular}

\begin{tabular}{|c|c|}
\hline \multicolumn{2}{|c|}{ Bend 7 Outside } \\
\hline \multicolumn{2}{|c|}{$\mathrm{D}_{50}=68 \mathrm{~mm}$} \\
\hline Size $(\mathrm{mm})$ & $\%$ Finer \\
\hline 512 & 100.0 \\
\hline 362 & 100.0 \\
\hline 256 & 98.0 \\
\hline 180 & 88.0 \\
\hline 128 & 68.0 \\
\hline 90 & 47.0 \\
\hline 64 & 21.0 \\
\hline 45 & 9.0 \\
\hline 32 & 1.0 \\
\hline 22.6 & 1.0 \\
\hline 16 & 0.0 \\
\hline 11.3 & 0.0 \\
\hline 8 & 0.0 \\
\hline
\end{tabular}




\begin{tabular}{|l|c|}
\hline River & Merced \\
\hline Location & Robinson Reach \\
\hline Date & April 2015 \\
\hline Observer & Emerson \\
\hline
\end{tabular}

\begin{tabular}{|c|c|}
\hline \multicolumn{2}{|c|}{ Bend 8 Inside } \\
\hline \multicolumn{2}{|c|}{$\mathrm{D}_{50}=48 \mathrm{~mm}$} \\
\hline Size $(\mathrm{mm})$ & $\%$ Finer \\
\hline 512 & 100.0 \\
\hline 362 & 100.0 \\
\hline 256 & 100.0 \\
\hline 180 & 100.0 \\
\hline 128 & 91.0 \\
\hline 90 & 74.0 \\
\hline 64 & 45.0 \\
\hline 45 & 20.0 \\
\hline 32 & 5.0 \\
\hline 22.6 & 0.0 \\
\hline 16 & 0.0 \\
\hline 11.3 & 0.0 \\
\hline 8 & 0.0 \\
\hline
\end{tabular}

\begin{tabular}{|c|c|}
\hline \multicolumn{2}{|c|}{ Bend 8 Middle } \\
\hline$D_{50}=50 \mathrm{~mm}$ \\
\hline Size $(\mathrm{mm})$ & \% Finer \\
\hline 512 & 100.0 \\
\hline 362 & 100.0 \\
\hline 256 & 100.0 \\
\hline 180 & 99.0 \\
\hline 128 & 89.0 \\
\hline 90 & 74.0 \\
\hline 64 & 41.0 \\
\hline 45 & 14.0 \\
\hline 32 & 4.0 \\
\hline 22.6 & 0.0 \\
\hline 16 & 0.0 \\
\hline 11.3 & 0.0 \\
\hline 8 & 0.0 \\
\hline
\end{tabular}

\begin{tabular}{|c|c|}
\hline \multicolumn{2}{|c|}{ Bend 8 Outside } \\
\hline$D_{50}=73 \mathrm{~mm}$ \\
\hline Size $(\mathrm{mm})$ & $\%$ Finer \\
\hline 512 & 100.0 \\
\hline 362 & 100.0 \\
\hline 256 & 96.0 \\
\hline 180 & 88.0 \\
\hline 128 & 70.0 \\
\hline 90 & 39.0 \\
\hline 64 & 15.0 \\
\hline 45 & 13.0 \\
\hline 32 & 10.0 \\
\hline 22.6 & 3.0 \\
\hline 16 & 0.0 \\
\hline 11.3 & 0.0 \\
\hline 8 & 0.0 \\
\hline
\end{tabular}




\begin{tabular}{|l|c|}
\hline River & Merced \\
\hline Location & Robinson Reach \\
\hline Date & April 2015 \\
\hline Observer & Emerson \\
\hline
\end{tabular}

\begin{tabular}{|c|c|}
\hline \multicolumn{2}{|c|}{ Bend 9 Inside } \\
\hline \multicolumn{2}{|c|}{$D_{50}=94 \mathrm{~mm}$} \\
\hline Size $(\mathrm{mm})$ & \% Finer \\
\hline 512 & 100.0 \\
\hline 362 & 100.0 \\
\hline 256 & 100.0 \\
\hline 180 & 82.0 \\
\hline 128 & 46.0 \\
\hline 90 & 26.0 \\
\hline 64 & 11.0 \\
\hline 45 & 4.0 \\
\hline 32 & 3.0 \\
\hline 22.6 & 0.0 \\
\hline 16 & 0.0 \\
\hline 11.3 & 0.0 \\
\hline 8 & 0.0 \\
\hline
\end{tabular}

\begin{tabular}{|c|c|}
\hline \multicolumn{2}{|c|}{ Bend 9 Middle } \\
\hline $\mathrm{D}_{50}=47 \mathrm{~mm}$ \\
\hline Size $(\mathrm{mm})$ & \% Finer \\
\hline 512 & 100.0 \\
\hline 362 & 100.0 \\
\hline 256 & 100.0 \\
\hline 180 & 99.0 \\
\hline 128 & 89.0 \\
\hline 90 & 67.0 \\
\hline 64 & 48.0 \\
\hline 45 & 21.0 \\
\hline 32 & 6.0 \\
\hline 22.6 & 3.0 \\
\hline 16 & 1.0 \\
\hline 11.3 & 1.0 \\
\hline 8 & 0.0 \\
\hline
\end{tabular}

\begin{tabular}{|c|c|}
\hline \multicolumn{2}{|c|}{ Bend 9 Outside } \\
\hline \multicolumn{2}{|c|}{$\mathrm{D}_{50}=53 \mathrm{~mm}$} \\
\hline Size $(\mathrm{mm})$ & \% Finer \\
\hline 512 & 100.0 \\
\hline 362 & 100.0 \\
\hline 256 & 100.0 \\
\hline 180 & 95.0 \\
\hline 128 & 83.0 \\
\hline 90 & 65.0 \\
\hline 64 & 39.0 \\
\hline 45 & 25.0 \\
\hline 32 & 12.0 \\
\hline 22.6 & 6.0 \\
\hline 16 & 0.0 \\
\hline 11.3 & 0.0 \\
\hline 8 & 0.0 \\
\hline
\end{tabular}




\begin{tabular}{|l|c|}
\hline River & Merced \\
\hline Location & Robinson Reach \\
\hline Date & April 2015 \\
\hline Observer & Emerson \\
\hline
\end{tabular}

\begin{tabular}{|c|c|}
\hline \multicolumn{2}{|c|}{ Bend 10 Inside } \\
\hline \multicolumn{2}{|c|}{$D_{50}=60 \mathrm{~mm}$} \\
\hline Size $(\mathrm{mm})$ & $\%$ Finer \\
\hline 512 & 100.0 \\
\hline 362 & 100.0 \\
\hline 256 & 100.0 \\
\hline 180 & 98.0 \\
\hline 128 & 77.0 \\
\hline 90 & 55.0 \\
\hline 64 & 33.0 \\
\hline 45 & 14.0 \\
\hline 32 & 5.0 \\
\hline 22.6 & 1.0 \\
\hline 16 & 0.0 \\
\hline 11.3 & 0.0 \\
\hline 8 & 0.0 \\
\hline
\end{tabular}

\begin{tabular}{|c|c|}
\hline \multicolumn{2}{|c|}{ Bend 10 Middle } \\
\hline \multicolumn{2}{|c|}{$\mathrm{D}_{50}=58 \mathrm{~mm}$} \\
\hline Size $(\mathrm{mm})$ & \% Finer \\
\hline 512 & 100.0 \\
\hline 362 & 100.0 \\
\hline 256 & 100.0 \\
\hline 180 & 99.0 \\
\hline 128 & 83.0 \\
\hline 90 & 60.0 \\
\hline 64 & 27.0 \\
\hline 45 & 11.0 \\
\hline 32 & 3.0 \\
\hline 22.6 & 0.0 \\
\hline 16 & 0.0 \\
\hline 11.3 & 0.0 \\
\hline 8 & 0.0 \\
\hline
\end{tabular}

\begin{tabular}{|c|c|}
\hline \multicolumn{2}{|c|}{ Bend 10 Outside } \\
\hline $\mathrm{D}_{50}=77 \mathrm{~mm}$ \\
\hline Size $(\mathrm{mm})$ & $\%$ Finer \\
\hline 512 & 100.0 \\
\hline 362 & 100.0 \\
\hline 256 & 100.0 \\
\hline 180 & 92.0 \\
\hline 128 & 65.0 \\
\hline 90 & 36.0 \\
\hline 64 & 10.0 \\
\hline 45 & 3.0 \\
\hline 32 & 1.0 \\
\hline 22.6 & 0.0 \\
\hline 16 & 0.0 \\
\hline 11.3 & 0.0 \\
\hline 8 & 0.0 \\
\hline
\end{tabular}

